\title{
التربية المتحفية للطفل
}

د. أحلام عبدالعظيم

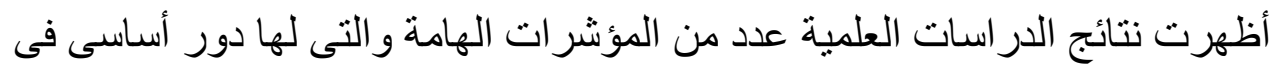

تنمية طاقات وقدرات الطفل الإبداعية من خلال الجماليات باعتبار ها مصدرًا أساسيًا لتربية وتثقيف الأجيال جماليًا، وتحقيق التو اصل وقد كانت أهم المؤشر ات ممثلة في التالى :

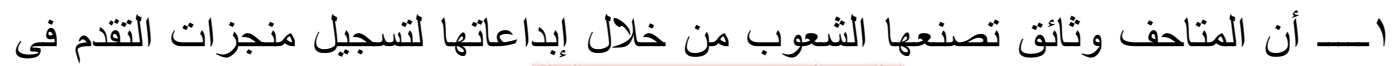
كافة مظاهر الحياة وما يتصل بذلك من أرصدة تاريخية ونية ونقافية وجمالية.

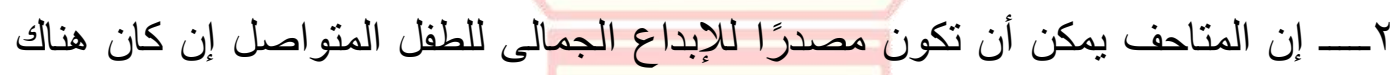
تربية متحفية تعد من خلالها الأجيال.

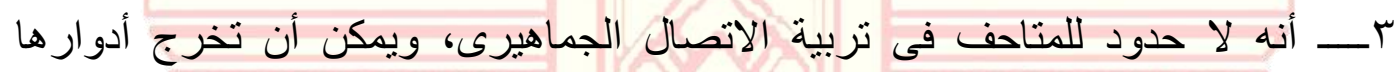

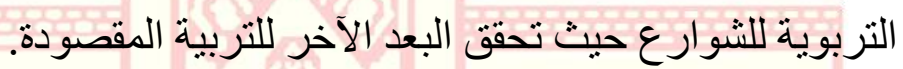

عـــ أن المتاحف هى المصدر الأساسى للتنمية الإبداعية والجمالية للطفولة وتعليمها و الحفاظ على الهوية الذاتية لثقافات الثعوب مستقبلاً.

○ـــأن المتاحف أحد المتطلبات الأساسية، لتوثيق مسيرة الثعوب وهى الحافز على التنمية الجمالية للطفولة وما بتصل بها من ثقافات للحو اس.

7ـــ المتاحف مر اكز أساسية لتحقيق التواصل بين الأجيال من خلاله الطفولة. ونستطيع الاستفادة من المتاحف بعلاقتها بالمدرسة من خلة الكل : ا ـــ توصيل المفاهيم المرتبطة بالملاحظة والتجربة والمعرفة وذلك من خلال أنشطة أو الو جو لات إرشادية، وبمعنى آخر تقديم الأنشطة بالوسائل المتحفية المتخصصة ولهية

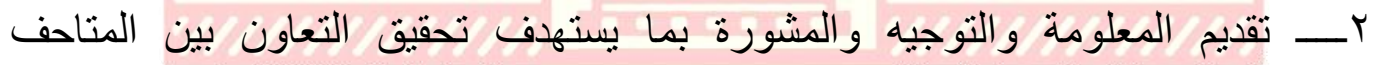

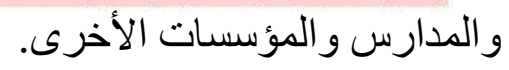

\section{r- تبنى المقترحات التربوية بخصوص نتشكيل وبناء المعارض.}

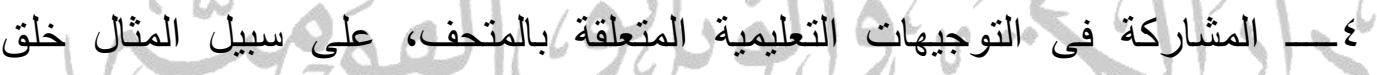
مجمو عات مشنركة بين إدارة المتحف و المدرسين. 0ــــالتعاون و المشاركة فى مجال تدريس وتعليم التربية المتحفية لكل هيئة التدريس. ويستطيع الطفل من خلال احتكاكه بالمتحف أن يتعلم الحوار المرئى بسر عة إلى حد ما وبنفس القدر يتفهمه ويطبقه على ما عداه من المعارض.

وتسهم التربية المتحفية فى نمو الإبداع الجمالى القومى و العالمى والثقافى و إتاحة الفرصة للتجريب والتفسير Interpretation والاطلاع و الربط بالعالم Wild life ومعرفة مسببات

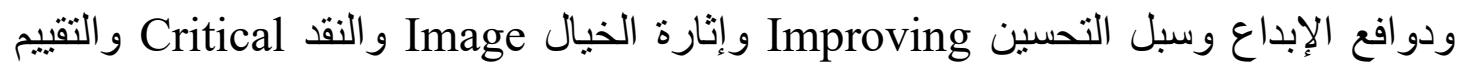


Evaluation

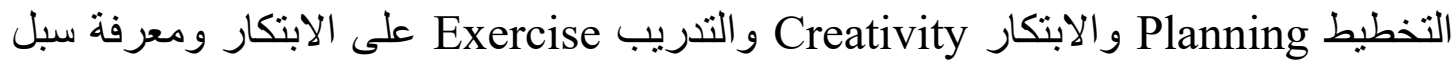

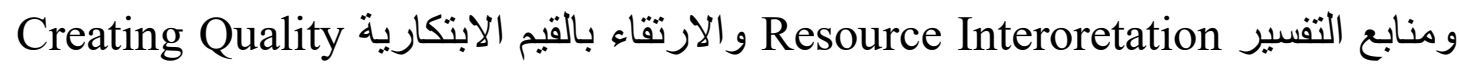
وتدريب الطفل على وضع بدائل Alternative فى المجالات الإبداعية بكفاءة أبعاده الجمالية المختلفة والتي تسهم فى تربية القيم.

و التربية المتحفية تستند فى فلسفتها على غايات مؤداها استثمار القدرة على التقييم واستخدام

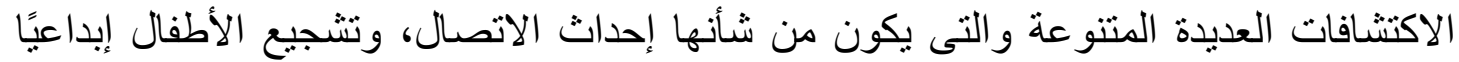
على البحث وتأكيد التتمية الإبداعية للطفل.

وتكمن فلسفة التربية المتحفية لتنمية إبداع الطفل فى تحقيق عدد من الغايات وهى : أــتنمية التفكير البصرى و الإبداعى للطفل بما يحقق ارتقاء لغته الجمالية.

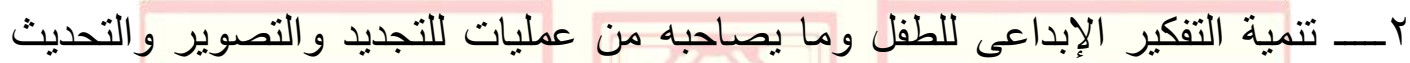

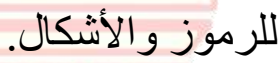
rـــتمية الحساسية الجمالية للطفل تجاه مدركات بيئية، وتمكينه من الحفاظ عليها.

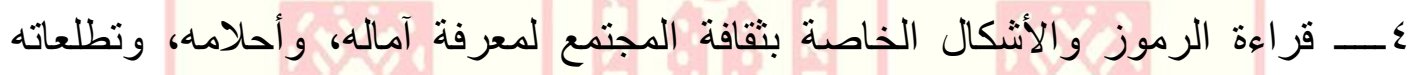
و أنظمة تفكيره، و ولسفته فى الحياة.

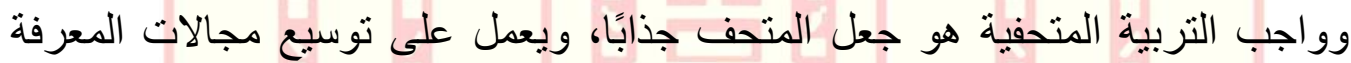
المختلفة كحق منساو للمو اطنين، بحيث يصبح لكل المستويات الثقافية على السو اء أمرًا مفهومًا.

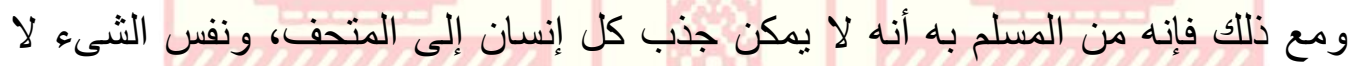

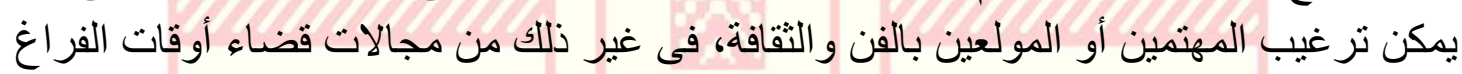

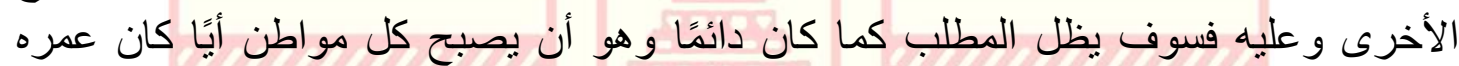

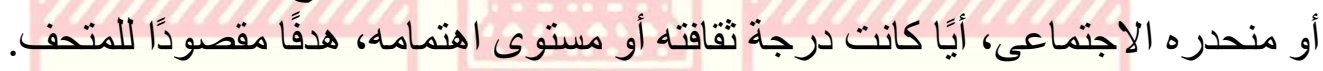

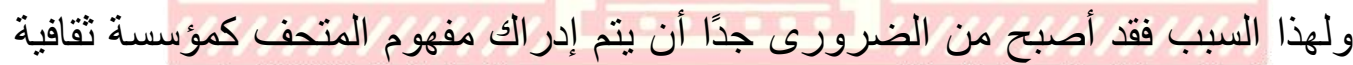
بالفعل بدءًا من مرحلة الطفولة، وأن يصبح مضمونه شيئًا محسوسًا وذللك عن طريق الدراك الملاحظة فالأشياء تصبح فقط محسوسة ومفهومه بكل معانى الكلمة وذلك ون ون طريق الملاحظة

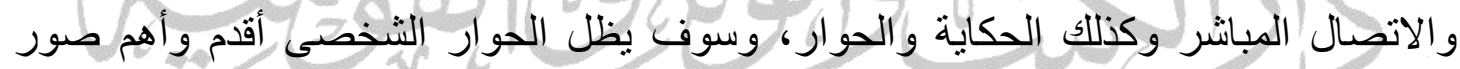

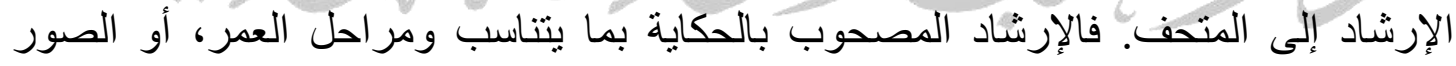

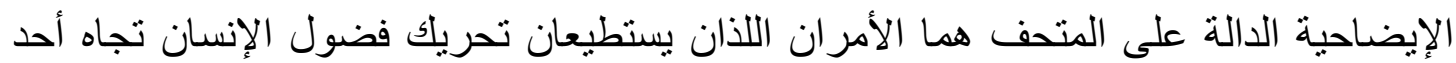

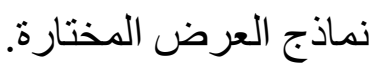




\section{وتستخدم التربية المتحفية طريقتين للتوصيل :}

أـ التوصبل الشخصى :

بالنسبة للتوصيل الشخصى فإن ترسيخه وتلقينه بشكل معقول يمكن أن يتم عن طريق

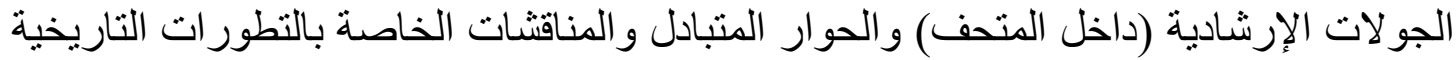

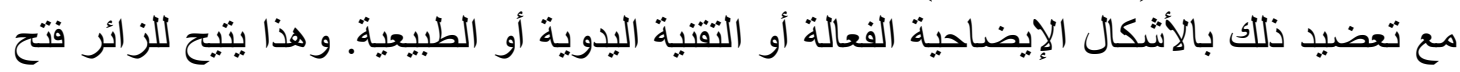
مجالات جديدة للمعرفة و المعايشة عن طريق تجربته الخاطئة، وهو يمتلك في هذا الصدئ الصدد دائمًا إمكانية الحوار المباشر، على خلاف وسيلة التلقين وتوصبل المعرفة عن طريق وسائل الإعلام.

\section{بـ التوصيل الإعلامى :}

ولما كان من المعروف أنه ليس فى مقدور كل زوار المتحف، المشاركة فى الجولات

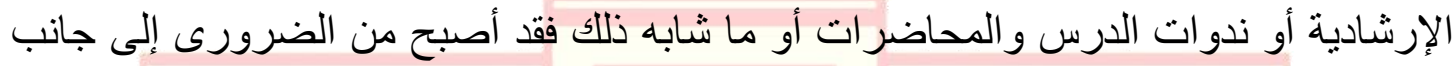

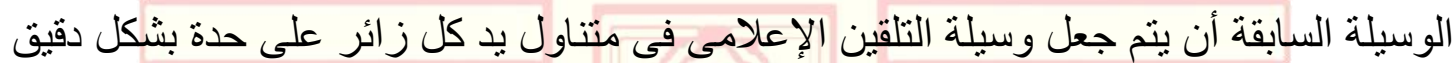

$$
\text { وشامل بقدر الإمكان. }
$$

\section{التربية المتحفية فع رياض الأطفال :}

أصبحت التربية المتحفية ضرورة فى تربية الأطفال منذ الصغر لاور ها الو اضح فى تتمية

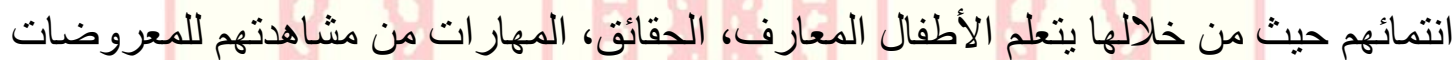

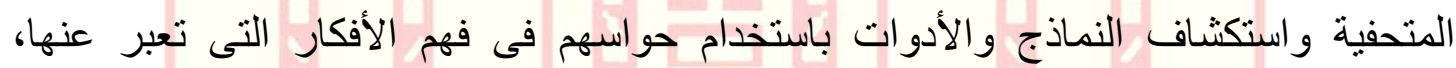
وممارستهم للأنشطة التى تساعدهم على إثراء وتدعيم معلوماتهم ومعار فهم.

ولذلك نادت منظمة الأمم المتحدة للتربية و العلوم و التقافة United Nation Educational (Scientific and Culture Organization (UNESCO ميثاقها بضرورة الاهتمام بالتربية المتحفية للطفل، وأسس المجلس العالمى للمتاحف International Council of Museums

\section{تعريف التربية المتحفية للطقل :}

عرفت كريستين ليبرثس Chr.liebertz التربية المتحفية بأنها "مبدأ يتداخل ويتشابك مع طريقة استخدام نماذج العرض بالمتحف، بمعنى آخر مع تقريبها أو توصيلها إلى زائر آخر ، وبالتالى يسعى المتحف إلى تحقيق أهداف تربوية علمية و أهداف تربوية ديمقر اطية وجعلها و اقعًا ملموسنًا".

وقد تعددت تعريفات التربية المتحفية للطفل، فيرى البعض بأنها "بر امج تعليمية تربوية هدفها

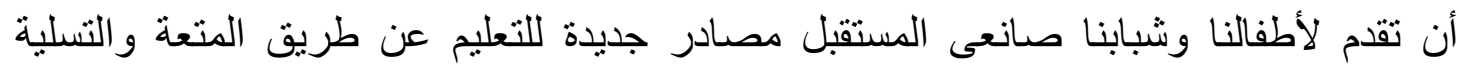

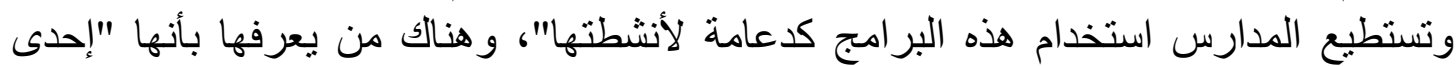

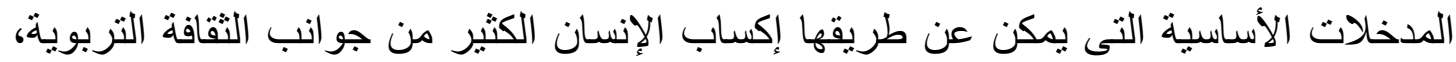
فالتربية قيمة فى حد ذاتها ويجب على المتاحف توجيه طاقتها نحو ها".

ويؤكد آخرون أنها "مجموعة الخبرات المقدة للأطفال من خلال زيارتهم للمتاحف 
وملاحظتهم وتجريبهم لنماذج المعروضات باستخدام حواسهم المختلفة لاكتشاف خواصها و الصفات المميزة لها وممارستهم الأنشطة التطبيقية، وذلك بهدف إثباع حاجات الأطفال إلى بـى إنى

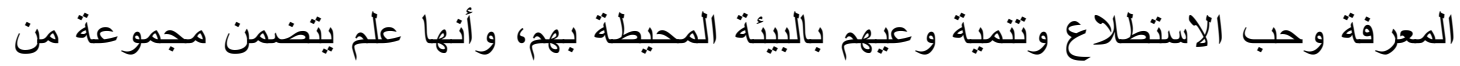
الخبر ات التربوية التى بمكن تقديمها لطفل الروضة بحيث تعمل وعل على تنمية الانتماء لديه و إكسابه العديد من المعارف و المعلومات فى إطار من المتعة و التسلية".

و هى أيضًا شرح المتاحف ومقتتياتها للأطفال بشكل مبسط بالاستعانة بالوسائل التعليمية المختلفة من مرئية ومسمو عة، وملموسة، وللتعلم باليد أو بأسلوب اصنع بنفسك.

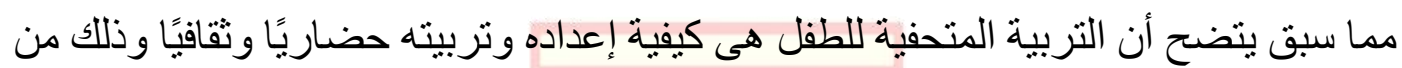
خلال العلاقة المباشرة بين الطفل و المتحف على ألا يصبح التعليم والنشاط المتحفى تكر ارًا للتعليم

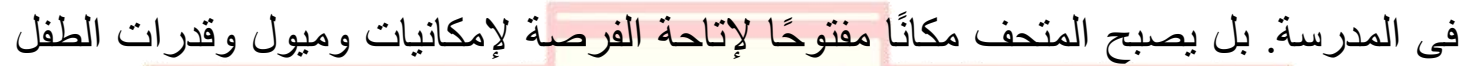

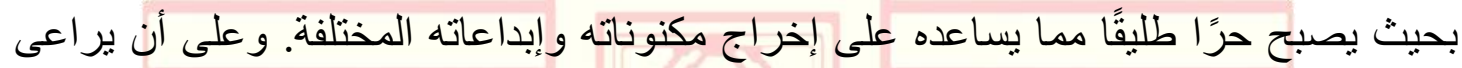

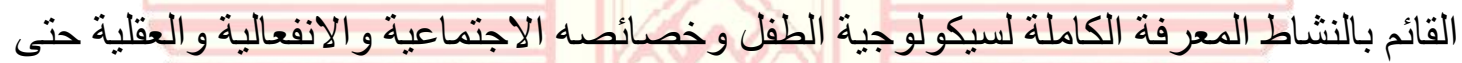

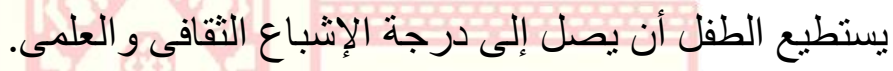

ومما سبق نجد أن التربية المتحفية هى الجسر الذى يربط بين الطفل و المتحف من خلال ما

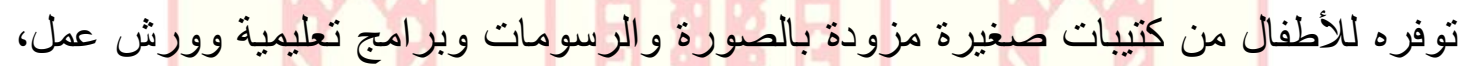

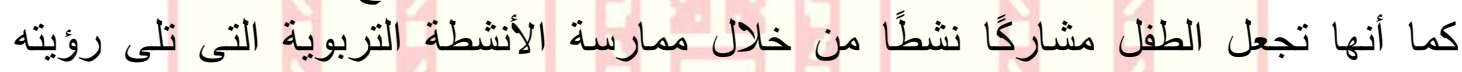
لمعروضات ونماذج المتحف، كما نجد دور ها البارز فى تزويد الطفل بقرات التفكير والنقا و البحث و الابتكار .

\section{أهداف التربية المتحفية فحى رياض الأطفال :}

1 - تأكيد الهوية القومية والأصول الثقافية للطفل :

حيث يساعد المتحف على تأكيد هوية الأطفال وتعريفهم على تاريخ حضارة وطنهم وتمييز الاختلاف بين ثقافتهم و الثقافات الأخرى.

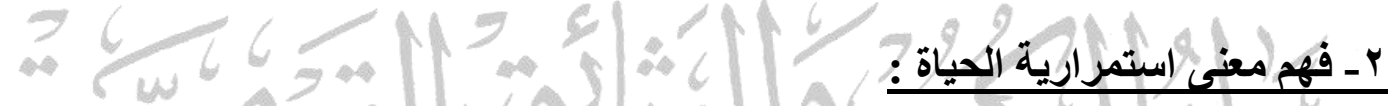

حيث تساعد التربية المتحفية الأطفال على تتبع المير ثاث الحضارى والتاريخى و على فهم

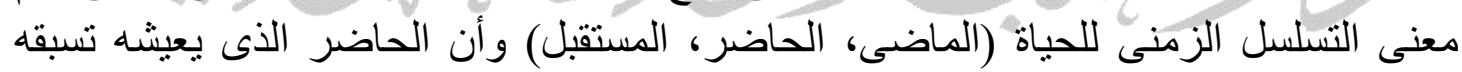
حضار ات أخرى قديمة.

\section{بـ تنمية الفكر والمعرفة : بـ}

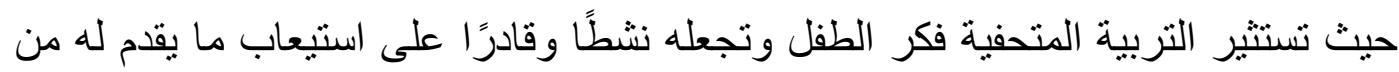

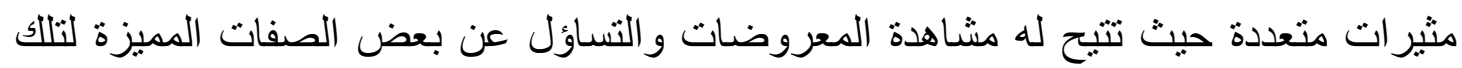

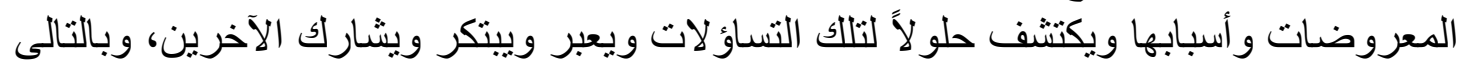
يقوم الطفل بعمليات التفكير العلمى من فهم و استنتاج و ابتكار. 


\section{عـ ممارسة الأنثطة التعبيرية و الفنية :}

حيث بسمح للطفل بلمس المعروضات ورؤيتها ليشعر بالمادة المصنوعة منها ويدرك

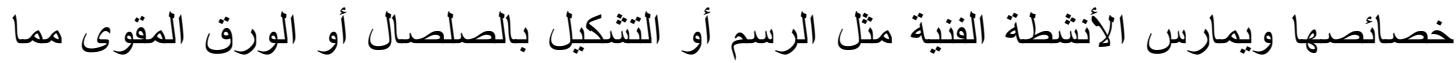
يمكنه من التوصل إلى حلول وأفكار جديدة مبتكرة واستخدام مهاراته الحركية والحسية الحسية و الإدر اكية فى تجسيد أحاسيسه و انفعالاته و معار فه تجاه المعروضات وضات و النماذج.

\section{هـ قضاء وقت الفراغ بطريقة مسلية :}

تساعد التربية المتحفية الطفل على قضاء وقت فراغه بطريقة مسلية وممتعة بمعايثته

$$
\text { لموضو عات من مواقف الحياة. }
$$

\section{ד- حماية البيئة :}

يساعد المتحف على توضيح ملامح البيئة التاريخية لكل شعب، ويظهر ذلك بوضوح فى التى متاحف التاريخ الطبيعى فيتخير المربى المتحفى بر امج ترتبط بالمشاكل البيئية فى المجتمعات البئه لجذب الأطفال للمشاركة في الحفاظ على الحياة الطبيعية وتدريبهم على أهمية الحفاظ على البيئة. يتضح لنا مما سبق أن المتاحف غنية بالخبرات التعليمية و التربوية والثقافية والترفيهية كما

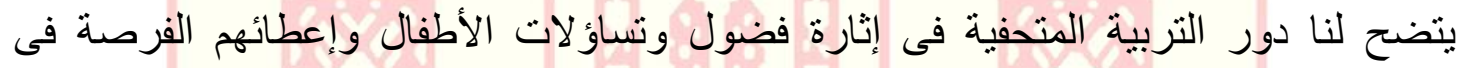
اكتشاف البيئة المحيطة بهر. وجود المتحف لا يهدف فقط إلى تعريف الأطفال بالتراث و الحضارة، ولكن يهدف إلى إلى تطوير قدرات الفرد البنائية، ولن يتحقق هذا إلا بإضافة أنشطة أخرى مثل الألعاب التركيبية

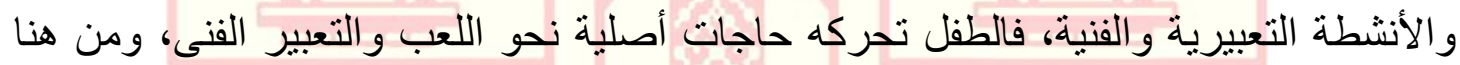

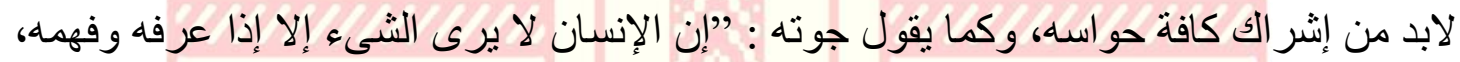
ومن هنا فالمتحف بالنسبة للطفل ليس مكانًا للزيارة ولكن مكانه وكان للتفاعل و المتعة وتربية الحاسة

$$
\text { الجمالية،"، }
$$

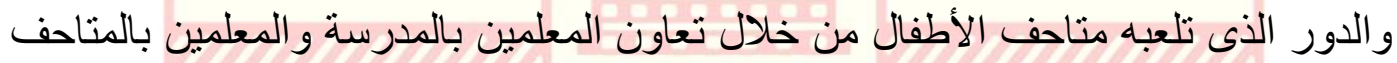

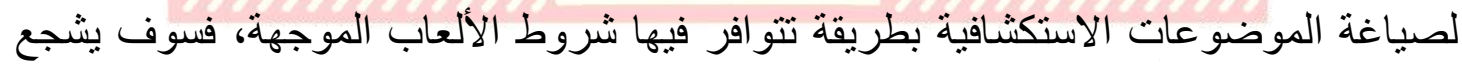
هذا على بناء خبر ات الأطفال والتعليم التلقائى لديهر، هذه البيئة تسهل إنماء وتأهيل العمليات

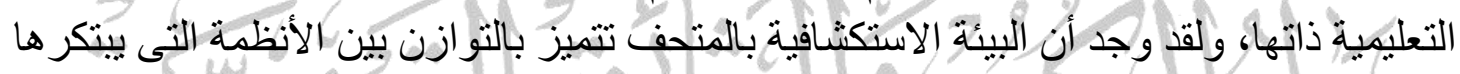

الكبار بالطرق المنظمة.

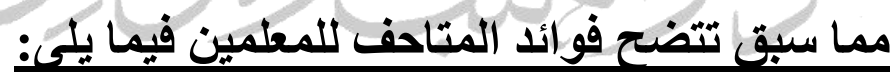

ا ـــــاحف المتاحت تمد المعلمين بإمكانيات إثر اء التعليم داخل الفصول.

r_ـــالمتاحف تساعد الزائرين فى تشكيل خبرات تعليمية من خلال ما يملكه المتحف من

$$
\text { ثروات. }
$$

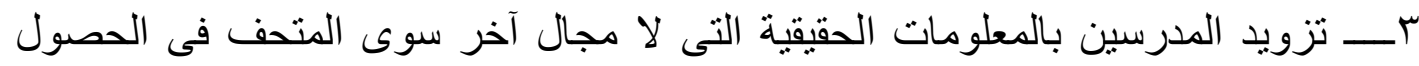
عليها.

وقد أوصث العديد من الدر اسات والأبحاث إلى ضرورة مر اعاة خصائص نمو الطفل عند 
زيارته للمتاحف وتدريب حواس الطفل الدختلفة و إثباع الحاجات الجسمية والعقلية والوجدانية

ومن هنا يأتى دور معلمة الروضة فى مر اعاة خصائص نمو الطفل عند زيارته للمتحف

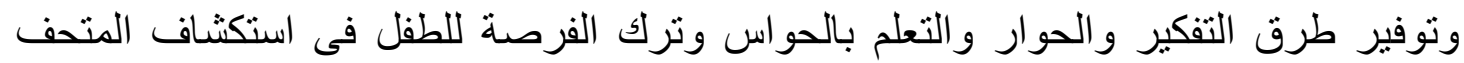

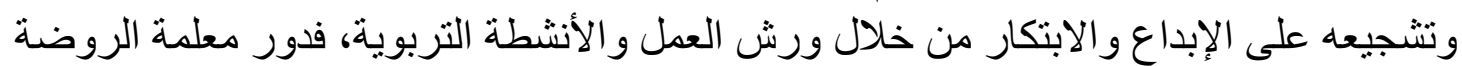

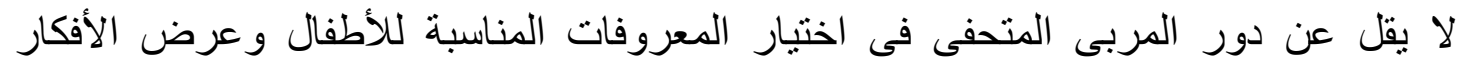

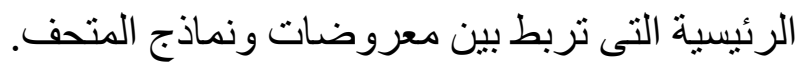

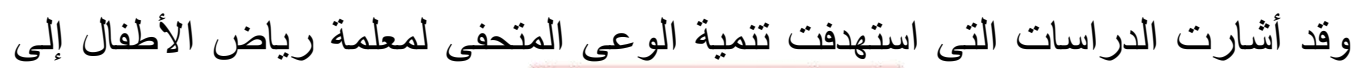

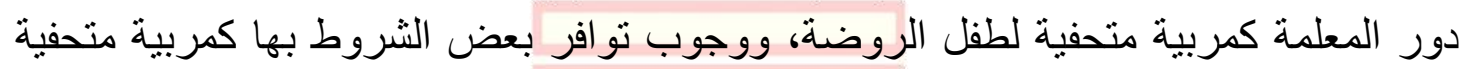

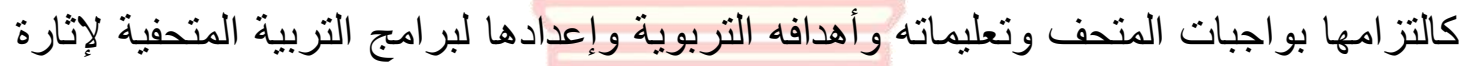

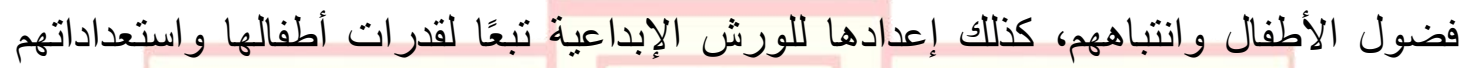

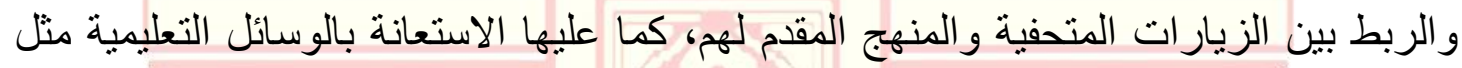

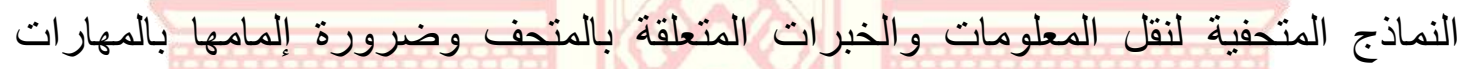
المعرفية و الفنية واليدوية والخبرات التى يمكن إكسابها للأطفال من خلال النماذج المناتحفية.

\section{نماذج لبرامج تربوية فى مصر :}

لا يوجد متحف فى العالم به قسم للآثار المصرية أو الإسلامية أو القبطية؛ إلا وبه برامج

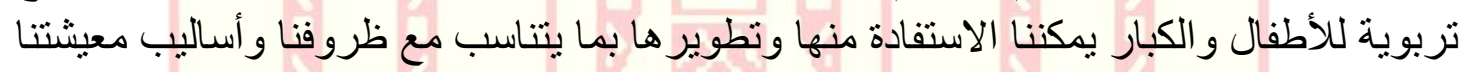
وتقاليدنا.

والأمثلة كثيرة جداً ومتتوعة؛ وإن كانت معظم البرامج مركزة على التاريخ الفرعونى،

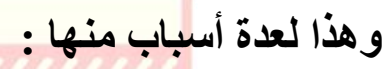

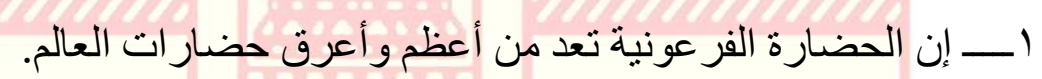

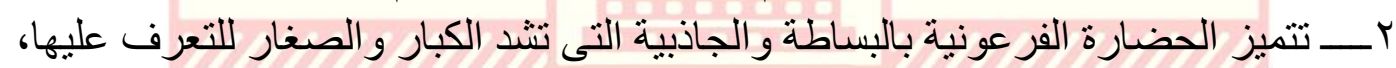

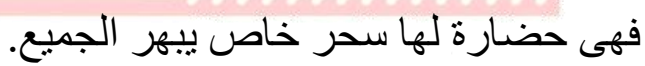

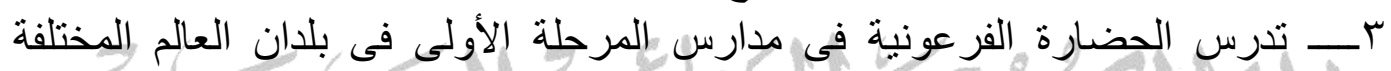

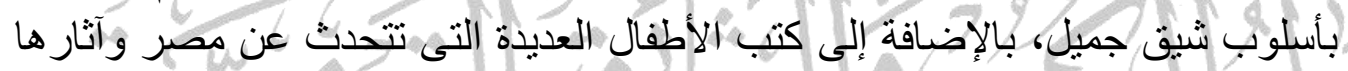
و القطص المأخوذة عنها.

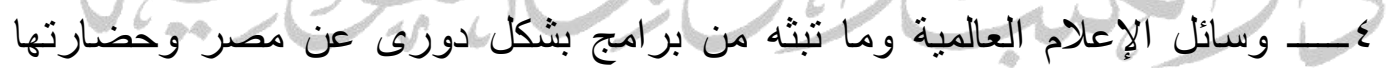

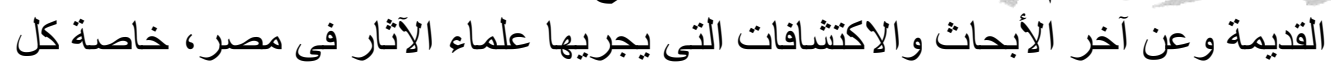

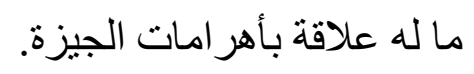

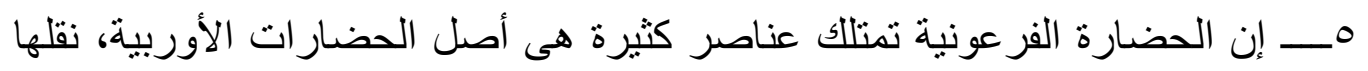

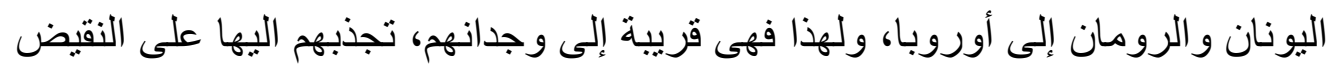

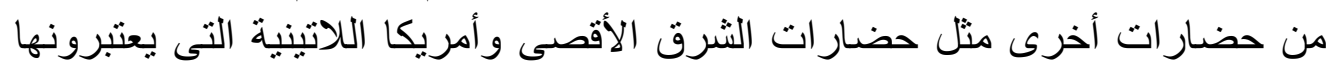

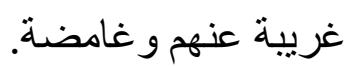
آـــ الحضارة الفرعونية لها وقع دينى خاص لارتباطها برسل و أنبياء ذكرت أسماؤهم فى الإنجيل والتور اة. 
و لأن مصر بلد ذو خصائص حضارية عديدة، وقد مرت عليها أحقاب تاريخية متتو عة. فإنه

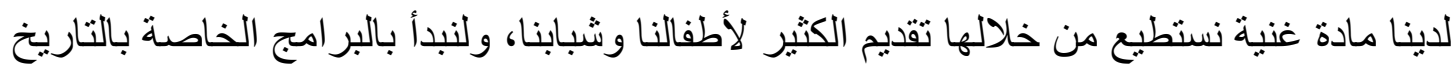

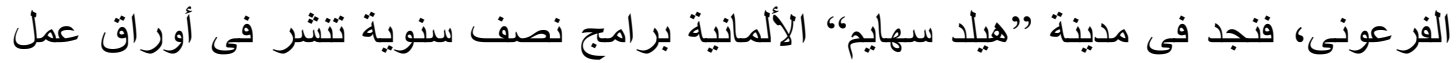

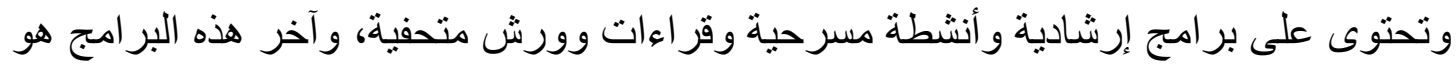

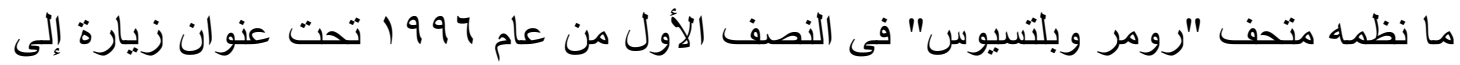
"حيت".

ويبدأ البرنامج برواية قصص من الأدب الفرعونى يقوم أحد المربين بسردها على الأطفال منها قصة "الملك و السحرة" المأخوذة عن بردية "وستكار "، التى ترجع إلى عصر الئى الأسرة الثانية

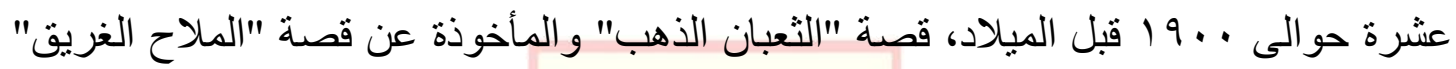

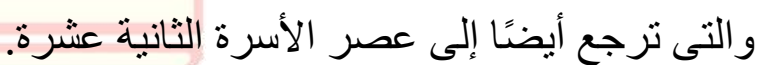

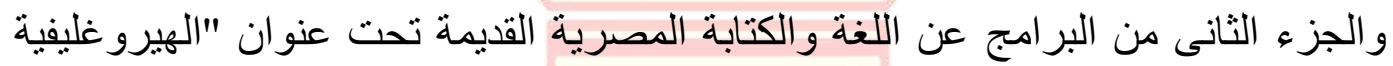

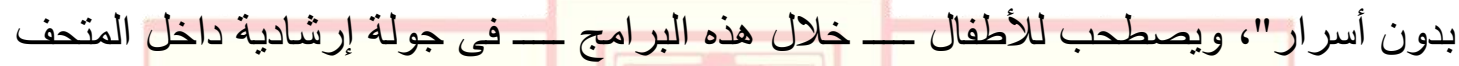

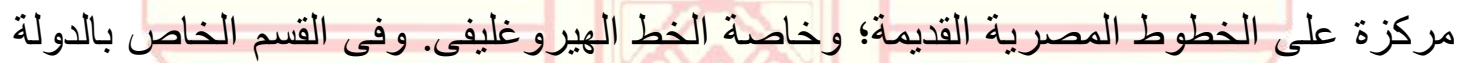
القديمة فى المتحف، يتعرف الأطفال على أهم عناصر اللغة المصرية القديمة وبعض قو اهية اعدها، و الهيرو غليفية من المجالات التى تجذب الأطفال كثيرًا ويتبادرون فى معر فتهاهيا. و هنالك جزء آخر من البرنامج عن الحياة اليومية في مصر القديمة، ويتم تقديمه من خلال

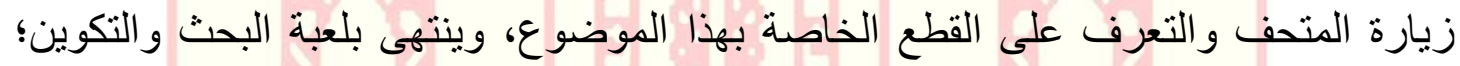

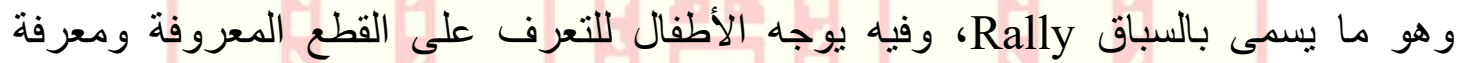

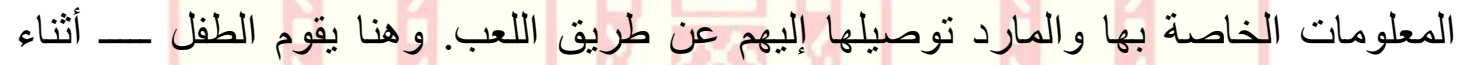

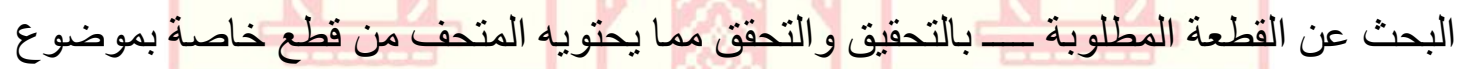

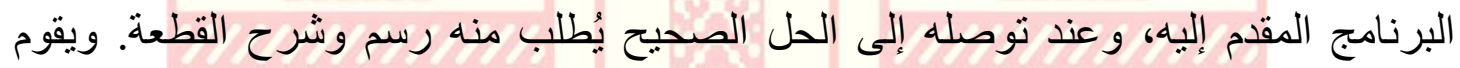
المربى المتحفى بتصحيح و إعطاء الجوائز للفائزين على شكل ملصقات جميلة أو بطاقات أو أو

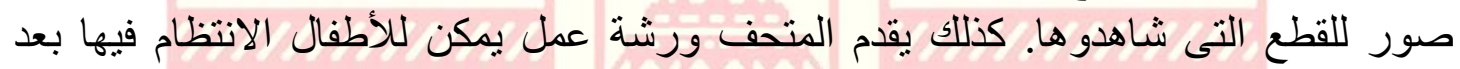
زيارة المتحف وممارسة أعمال الرسم والتشكيل بالصلصال أو الورق المقوى.

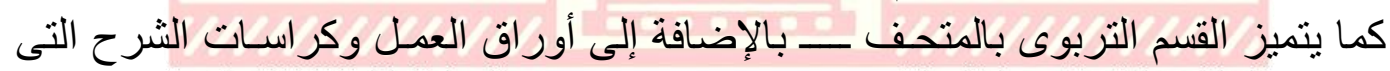

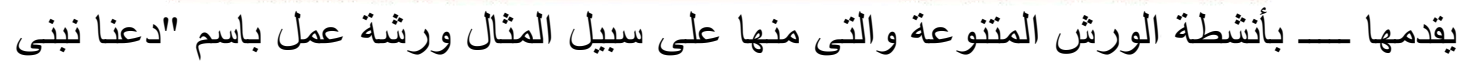

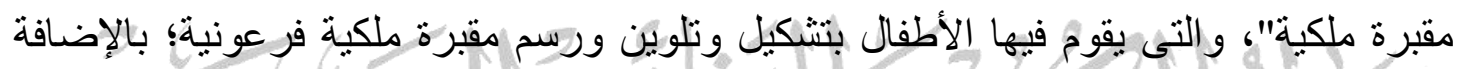
إلى حياكة المالابس المصرية القديمة، وتأدية مسرحيات من وحى التراث المصرى القديم والعقائد

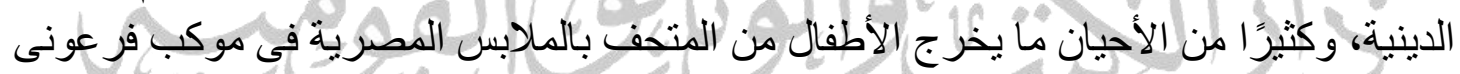

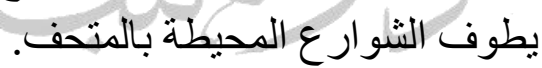
أما المتحف المصرى ببرلين، فيشتهر بكراسات العمل الجيدة التى قدمها فى برامجه التربوية، و التى تلقى نجاحًا كبيرًا فى المجال التعليمى التربوى؛ ليس فقط فى مدينة برلين؛ و إنما فى جميع المدن الألمانية.

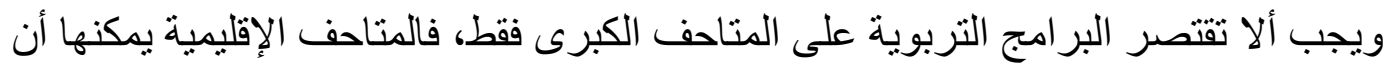

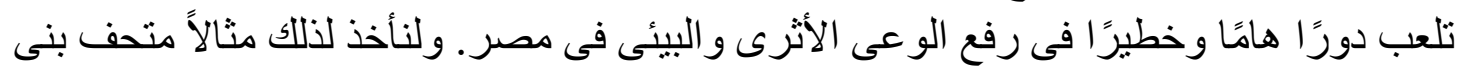

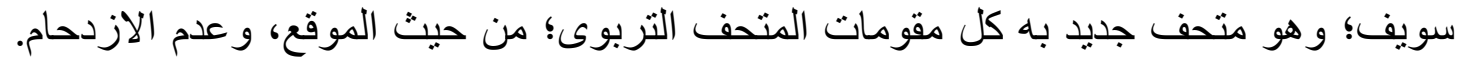

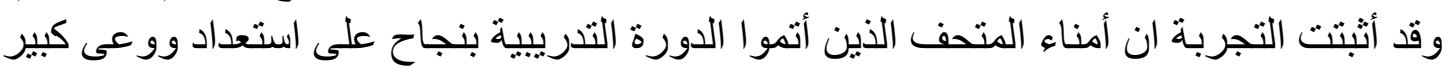
لتنفيذ المهمة التربوية الو اقعة على عاته عاهُ التهم. 


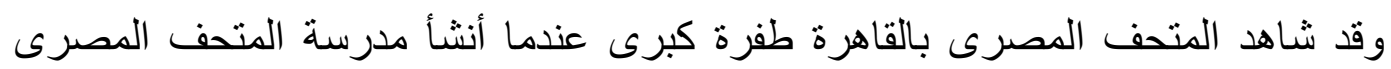

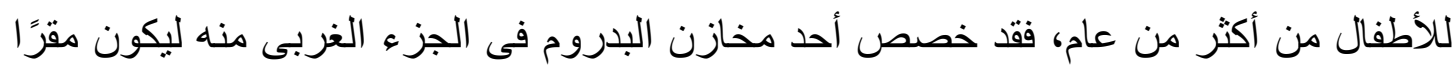

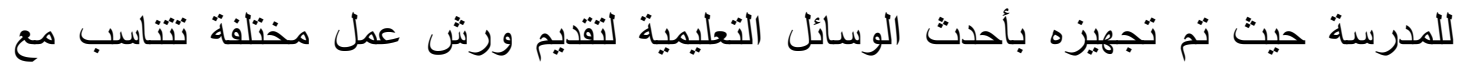

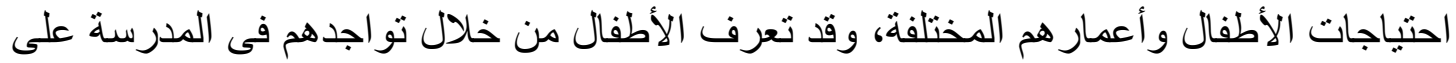

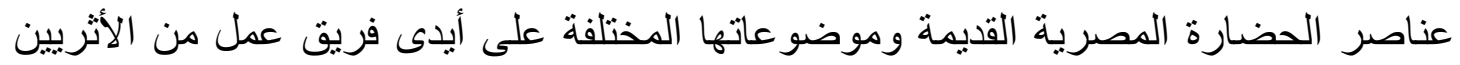

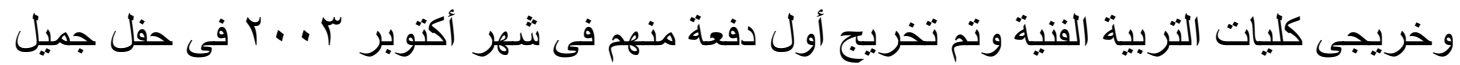

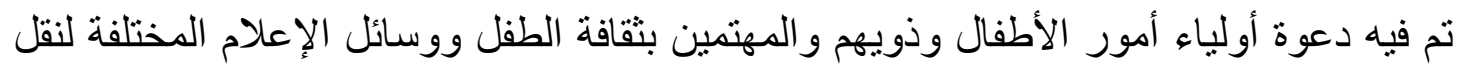

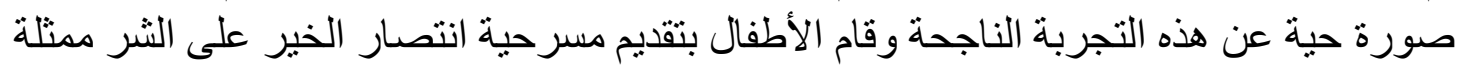

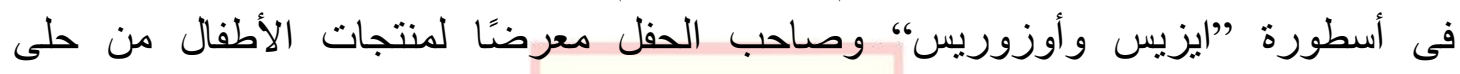

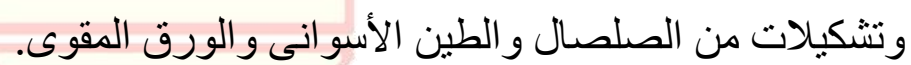

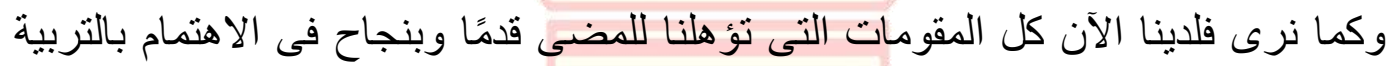

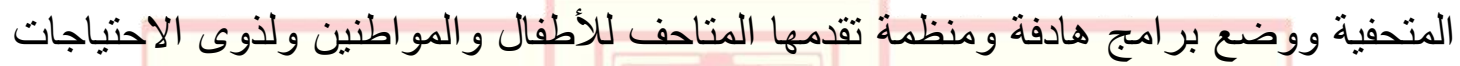

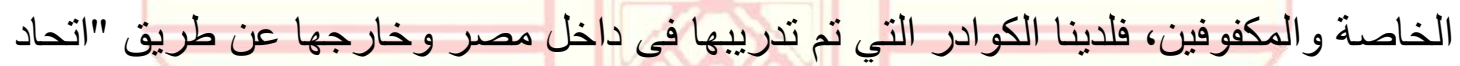

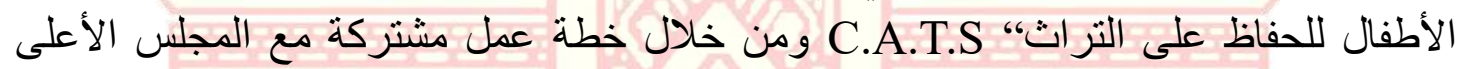

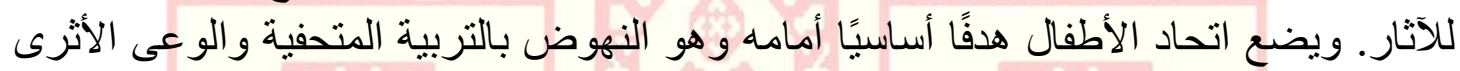

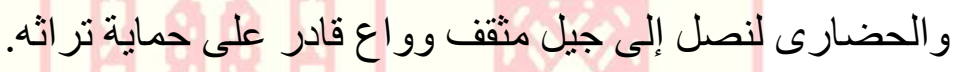

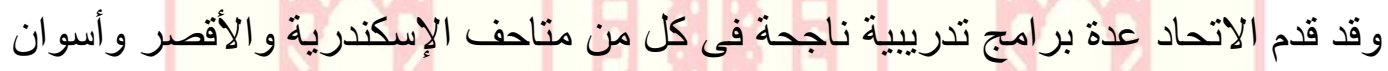

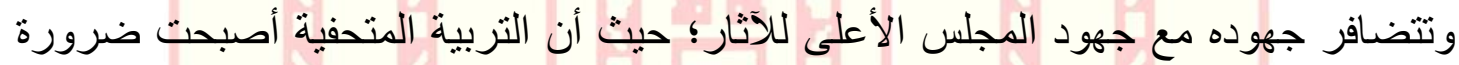

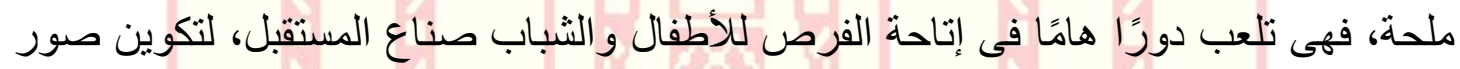

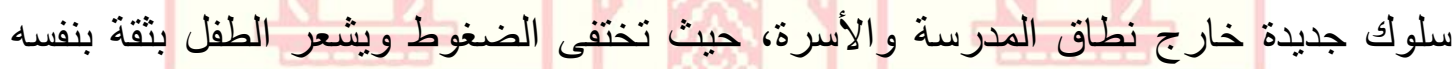

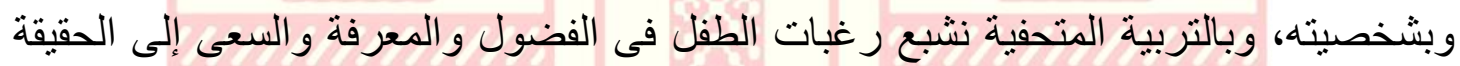

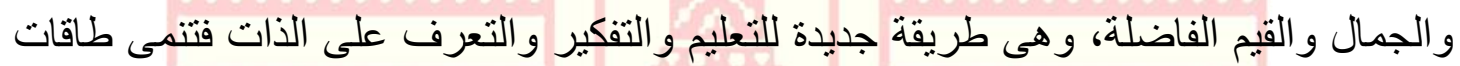

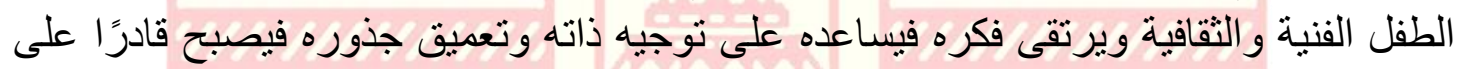

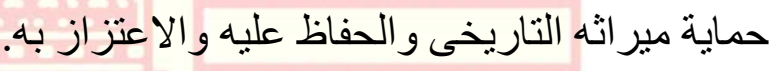

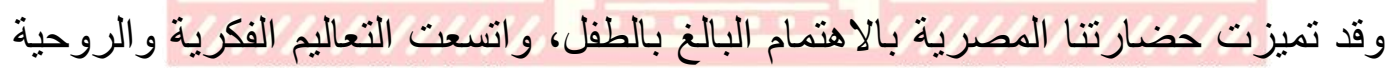

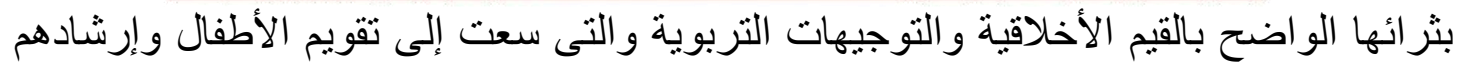

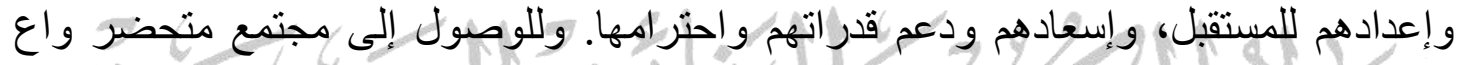

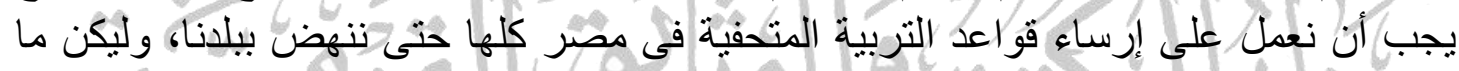

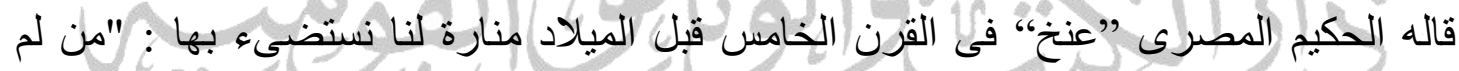

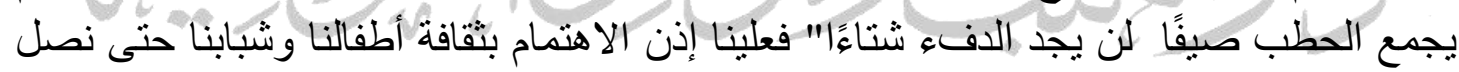

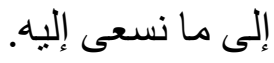

\section{أهداف الأنشطة المتحفية :}

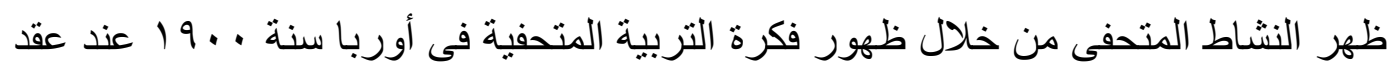

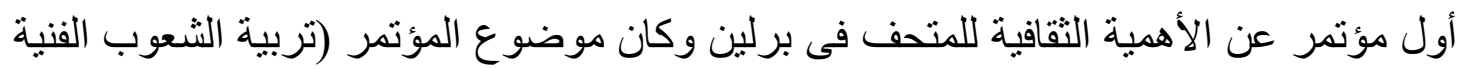

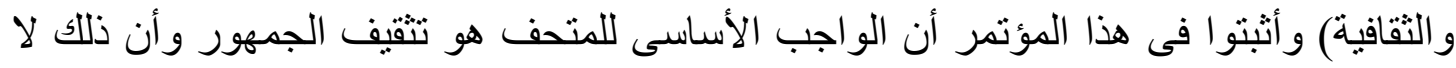

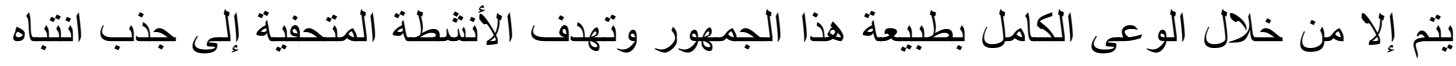




$$
\text { المشاهدين وتثقيفهم عن طريق : }
$$

اـــــقية الجهود على الملاحظة التثقيفية من خلال الجو لات الإرشادية فى المتحف.

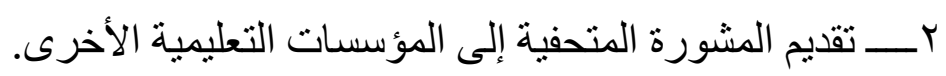

بــــالاستفادة من المقترحات التربوية التى يتقدم بها الزوار نحو شكل المتحف وبر امجه

$$
\text { التربوية. }
$$

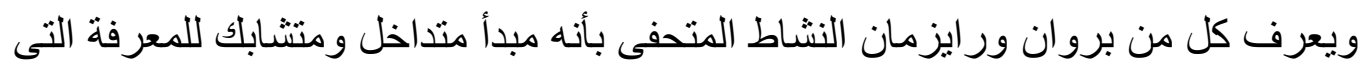

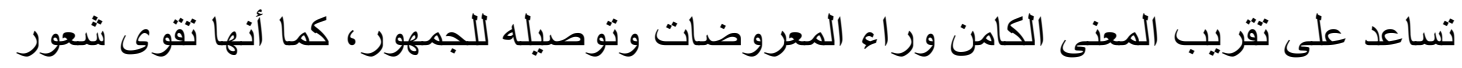
الفرد بأصالة مير اثث الثقافى وبناء على ذللك تغير المفهوم الوظيفى للمتحف. فلم تعد وظيفة المتحف مقتصرة على ربط الإنسان بماضيه بل امتدات لتربطه بمستقبله.

\section{ولضمان تحقيق أهداف النشاط المتحفى فإنه يجب على مسئول التربية المتحفية الآتى :}

أــ يجب أن بعد نفسه علميًا وثقافيًا فى مجال تخصصهه والاطلاع على سيكولوجية الطفولة العادية وغير العادية، والمشاركة الفعالة فى نشر الكتيبات العلمية و التربوية

$$
\text { و الكتالوجات. }
$$

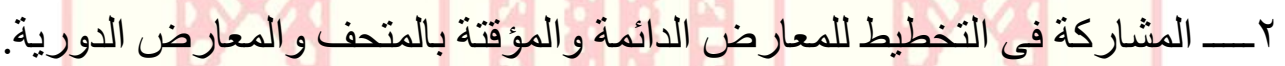
rـــــالاتصـال الدائم بالمؤسسات التعليمية والتربوية و الثقافية و الثبابية المختلفة. عــــتظيم بر امج معينة للمجمو عات ذات الاحتياجات الخاصة. 0ــــــيه الاهتمام للثباب و الأطفال الذين لم تتح لهم الفرصة لإتمام در استهم والمتسربين من التعليم.

\section{أهمية الأنشطة المتحفية :}

يرى و امبانش إن الأنشطة المتحفية تعمل على تشجيع التحرر البدنى والنفسى للفرد، وتتيح

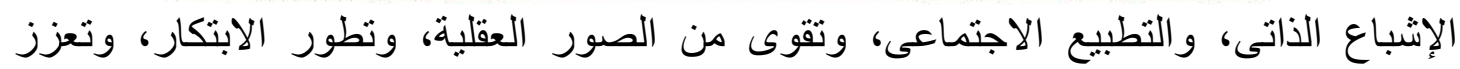

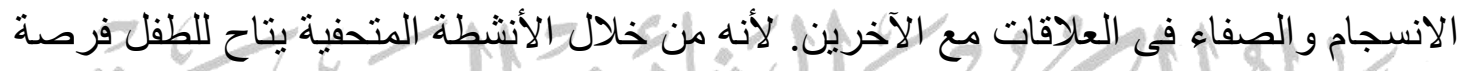

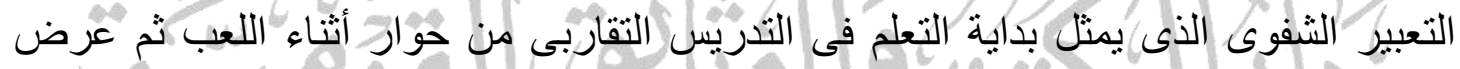

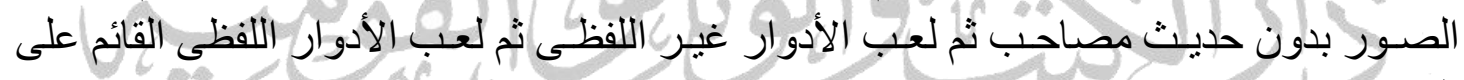

و التعبير الثفوى فى المتحف يهدف إلى تمكين الأطفال من إلقاء حكاية متماسكة، فهو يبعد

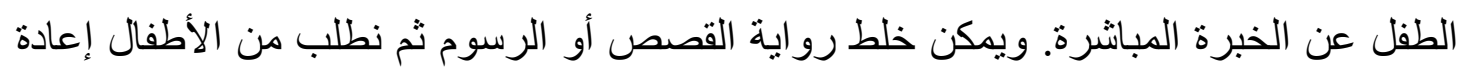

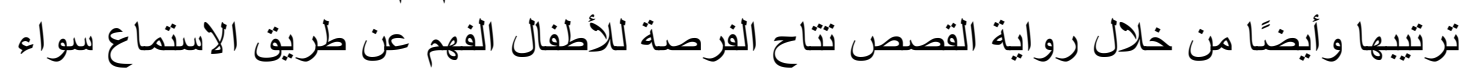

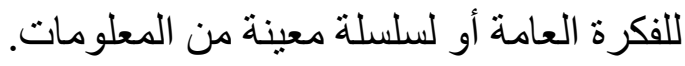
أما بالنسبة لمشروعات العمل داخل المدرسة فهى مشروعات كبيرة تتطلب وقتًا لإنجاز ها

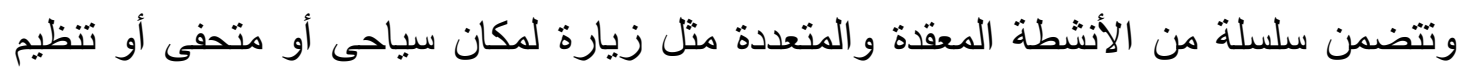


مهرجان مدرسى أو رعاية حديقة الددرسة أو تربية حيوانات أليفة على مستوى صغير. فإنه

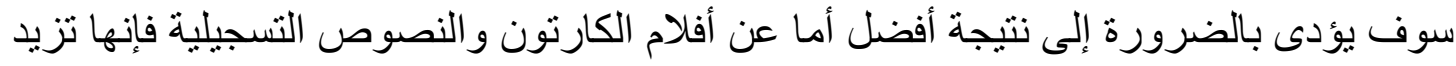
من فاعلية الأنشطة التعليمية للأطفال.

وعليه فالأنشطة المتحفية نوع من ألوان الممارسات التى تهدف إلى تحقيق النمو المتكامل

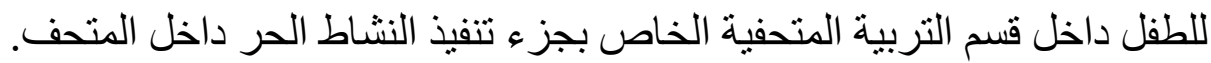

أنشطة المتحف:

\section{وتقوم المتاحف بالعديد من الأنشطة منها :}

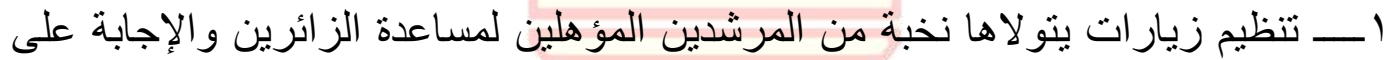
تساؤ لاتهم المتعلقة بتلك المجمو عات التهات الفنية.

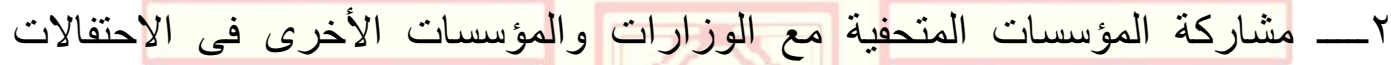
الرسمية المنعلقة بالأعياد القومية والدولية.

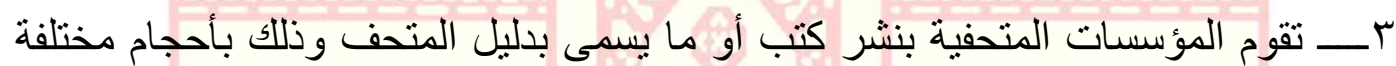

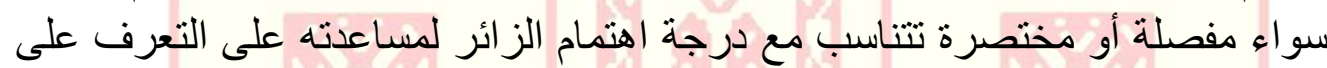
المتحف ومجمو عاته و أهميتها التاريخية و الفنية و الثقافية و الفنية.

عـــ إعداد المطبو عات المختلفة المتعلقة بالمتاحف و المو اقع الأثرية وتاريخ الثقافة والفنون بالإضافة إلى الثر ائح الضوئية والبطاقات.

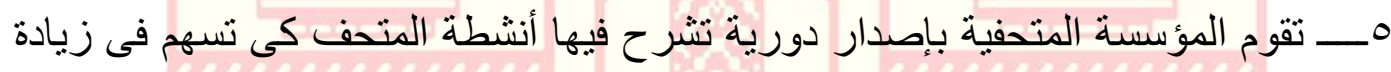

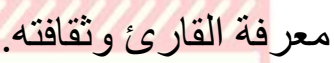

7ـــ تعد المتاحف ندو ات ومو اسم ثقافية يشترك فيها كبار المثققين مما يتيح لكثيرين فرصة

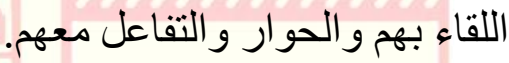
V_ الإعداد لمعارض ذات موضو عات محددة بجذب اهتمامات فئات المجنمع. ^ـــــاولة إثر اء مجمو عات المتحف كما يجب التعرف بالمقتتبات وذلك من خلال در استها 9- اقتناء أحدث الأجهزة المتعلقة بالأمن ووسائل الإضاءة والتدفئة و التهوية وتحديث المتحف بإستقرار ومو اكبة التكنولوجيا الحديثة.

• إ_ـ إقامة المعارض كما يجب تبادل إقامة المعارض مع المتاحف الأخرى محليًا ودوليًا وذللك لتجديد المعروضات الفماتية. 


\section{النثاط المتحفى فى جمهورية مصر العريية}

\section{مدرسة الفن بالمتحف المصرى بالقاهرة}

تأسست هذه المدرسة فى صيف سنة ب . ب وتهدف المدرسة إلى تتمية الوعى الحضارى

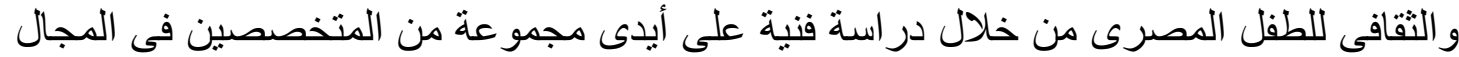

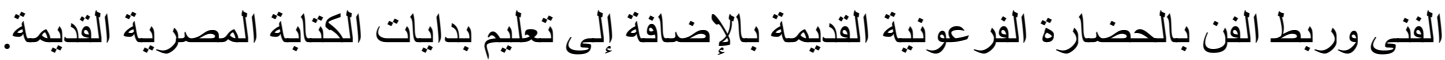

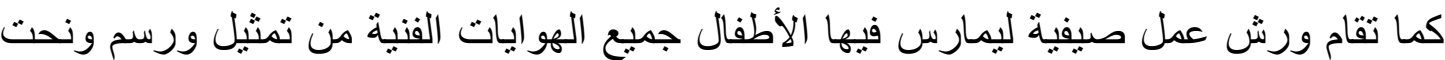
و أشغال يدوية و غير ها من الأنشطة المختلفة.

\section{متحف الطقل (سوزان مبارك) بمصر الجديدة}

متحف الطفل بمصر الجديدة هو مركز تعليمى وتثقيفى برحب بالأطفال فى عالم جذاب

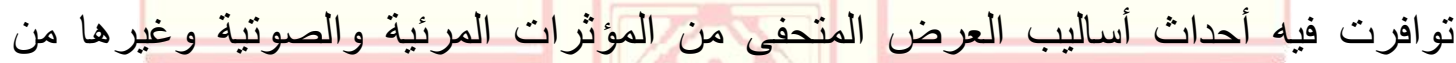

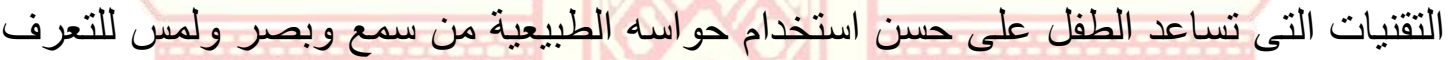
على الجديد مما يثير فيه الرغبة فى مزيد من المعرفة والثعور بالانطلاق و الثقة فى النفس.

و أول ما بشاهده الطفل عند مدخل المتحف هو نموذج مكبر لجواز السفر الذى سيحصل عليه

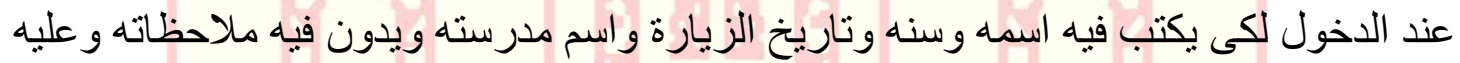
أن يحصل فى نهاية كل قاعة من قاعات المتحف على ختم خاص يدل على إتمام زيارته لهذه القاعة باستخدام الختامات المخصصة لهذا الغرض. يحتفظ الطفل بهذا الدفتر كذكرى لزيارته

وتهدف قاعة مصر الفرعونية تعريف الطفل كيفية استخدام البيئة الطبيعية المتمثلة فى مياه

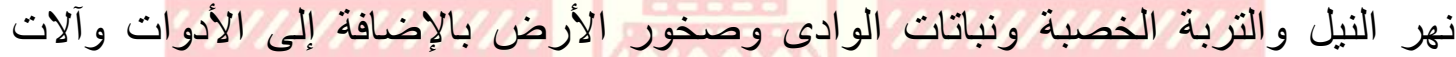
الزر اعة. ويلى ذلك عرض يوضح عمليات الغزل و النسيج وصناعة الملابس من ألياف النباتات.

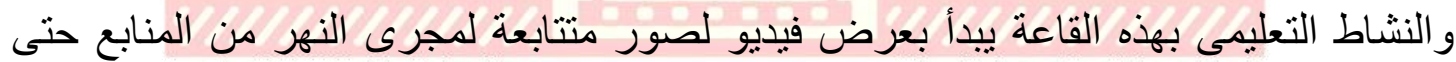
المصب تتخللها صور للحياة الحيو انية والنباتية التى تزدهر وتتمو فى مختلف المناطق بالإضـافة إلى حوار بين أطفال و ادى النيل بأشكالهم و أزيائهم المختلفة وليه

كما تهدف قاعة الصحراء إلى تعريف الطفل بطبيعة الصحارى المصرية وثرواتها وما تحتويه من نبانات وحيو انات تتأقل ظروف الصحر اء القاسية، ويجوب الطفل القاعة من خلال

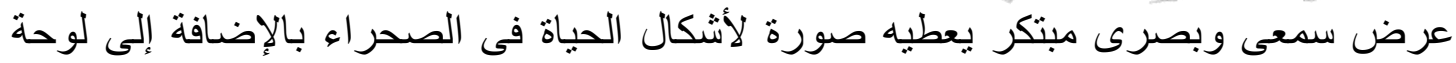

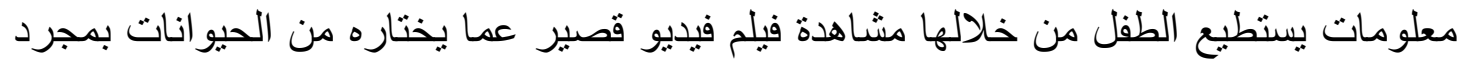

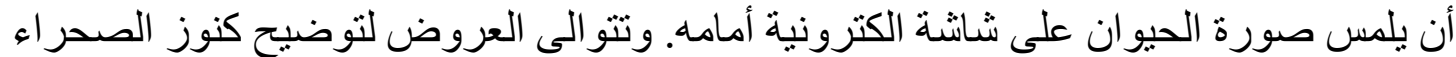
من معادن وأحجار شبه كريمة وخامات وملئ ومصادر للطاقة

\section{ويهوف مركز الأنشطة بالمتحف إلىى:}

إ-ــإتاحة التعليم الاختيارى الممتع القائم على أعمال أكبر عدد من الحواس فى اكتشاف مفردات البيئة الطبيعية والتفاعل معها بلمسها وقراعة النص المصاحب المباحب لها وتأملها 


$$
\text { بالعين المجردة أو العدسة المكبرة أو المجهر. }
$$

r ــــثف الكثف عن مو اهب الطفل الإبداعية فى مجلات التعبير الحر وتعريفه بالحرف البيئية

$$
\text { التقليدية البسيطة لكى يمارس ما يروقه منها. }
$$

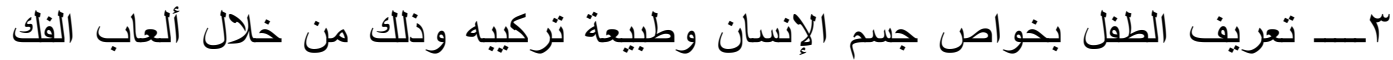

$$
\text { و التركيب. }
$$

\section{النشاط المتحفى فحى متحف بورسعيد القومى بمدينة بورسعيد :}

يتكون متحف بورسعيد القومى الذى يبلغ مساحته ب ا ألف متر مربع من سبعة قاعات

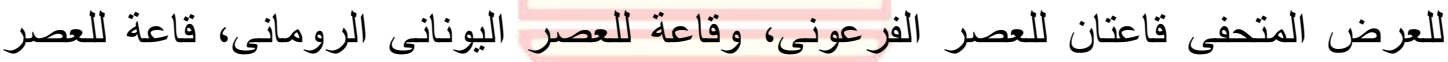

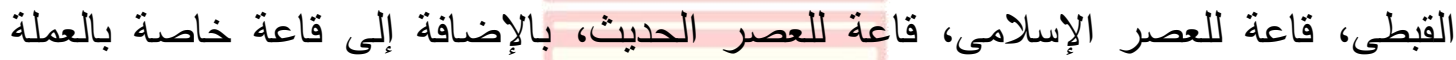
و المخطوطات وكذلك قاعة تسمى بقاعة الفيديو و المحاضر ات و هى القاعة المعدة بأحدث الأث أدو ات

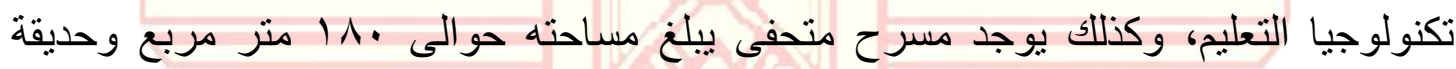
متحفية مساحتها حو الى 0 آلاف منر مربع تتيح الفرصة للقيام بنشاط منحفى يناسب مرحلة

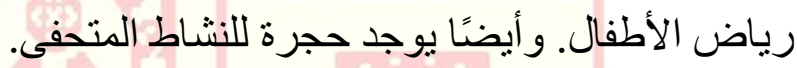

وقد بدأ متحف بورسعيد بتجربة رائدة فى مجال النشاط المتحفى منذ افتتاحه سنة 9Av 1 حيث تكونت مجموعة من الأطفال الر اغبين فى المشاركة بالنشاط المتحفى بتحقيق الأهداف التربوية

يتولى القائمون على أمر هذا القسم (قسم التربية المتحفية) إعداد موضوع الزيارة مع

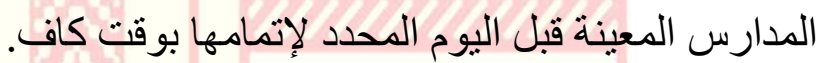

ويفضل أن يقدم لهذه المدارس خطة تشمل المواعيد والموضوعات والأنشطة التى يتم إجرائها فى هذا القسم. ويمكن تسهيل المهمة على المدارس و المر اكز الخاصة بالمكفوفين

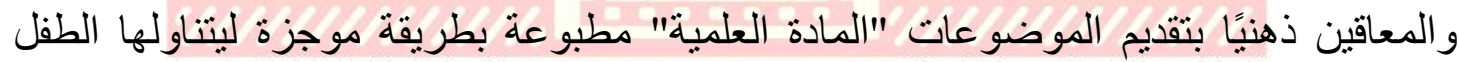

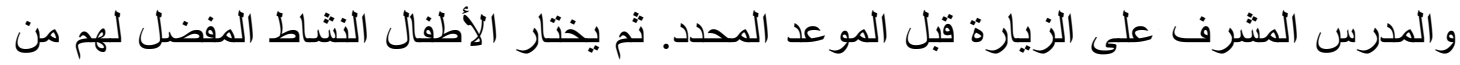

النحت بأنو اعه باستعمال الصلكال الملون و الطينى، الرسم والتلوين، النجارة البسبطة لتقليد

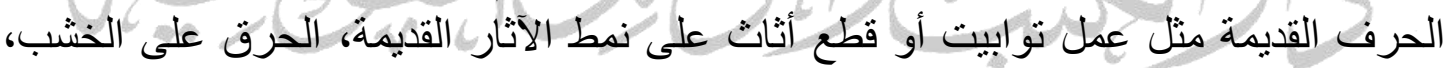
عمل مسرح عرائس، أشغال التجسيم بالورق (الكارتون)، أنواع الطباعة، ممارسة التمثنيل

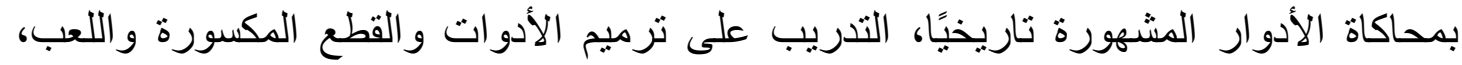
ممارسة نماذج للفك و التركيب على قطع الآثار المصنعة.

\section{برامج للأنشطة المتحفية فى متحف بورسعيد :}

ا ــــــر امج خاصة للأطفال صغار السن يتعرف فيه الطفل على أثنياء محددة تناسب سنه وتفكيره وتنمى فيه القدرة على الخيال والابتكار عن طريق لمس نماذج للأشياء. 
r- بـ برامج داخل المتحف تتيح الفرصة للأطفال عن معرفة بداية صناعة لعب الأطفال ومشاهدة اللعب الأثرية منذ العصر الفرعونى حتى العصر الحديث.

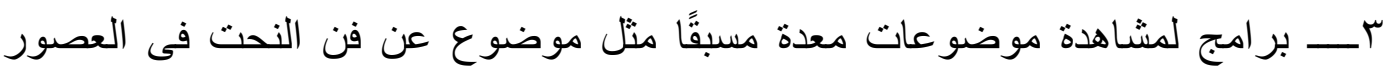

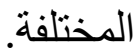

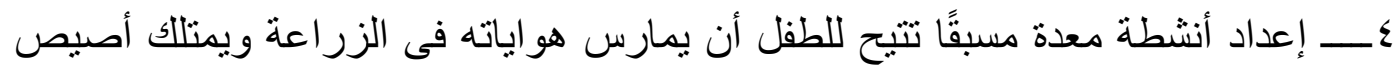

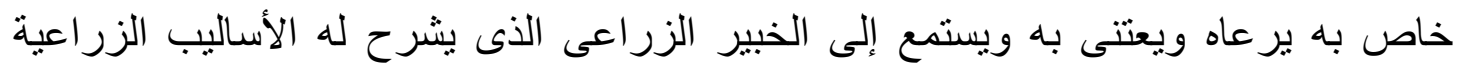
الحديثة و الأساليب الصحيحة لحفظ الحبوب.

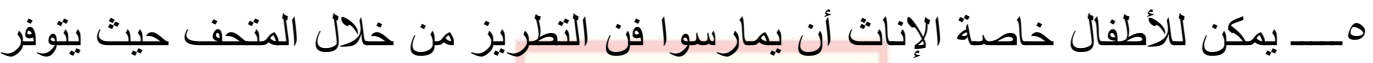
لهم مشاهدة التطريز من العصر الفر عونى حتى العصر الحديث. T- يمكن للطفل معرفة طرق صناعة الغزل والنسيج فى العصر الفرعونى.

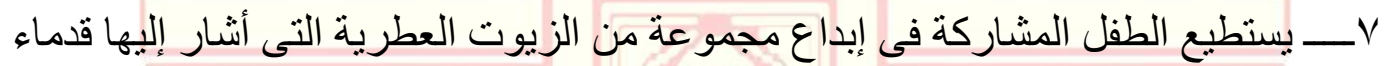
المصريين فى بردياتهم.

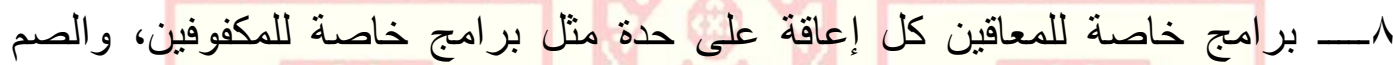
و والبكم، و المعاقين هنيًا.

\section{النشاط المتحفى فحى المتحف اليونانى الرومانى بمدينة الإسكندرية}

بدأ النشاط المتحفى فى المتحف اليونانى الرومانى فى صيف 1997 بأعمال مسرحية

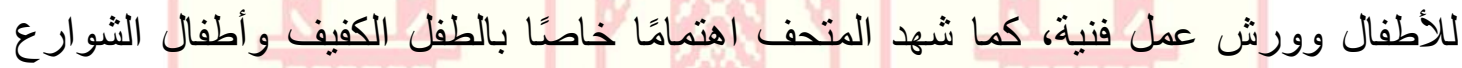
الذين تسربوا من التعليم وإدماجهم فى أنشطة متحفية مفيدة لهم. المشروع التعليمى بمتحف الأقصر بمدينة الأقصر

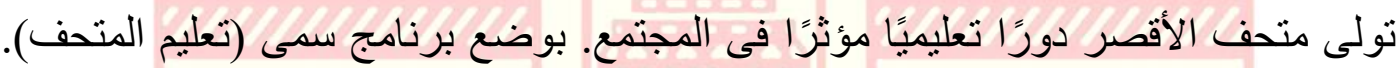

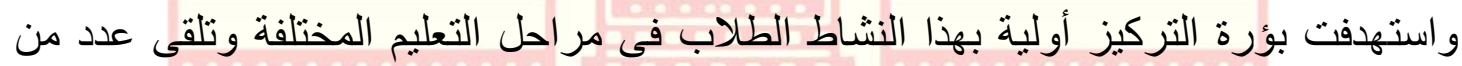

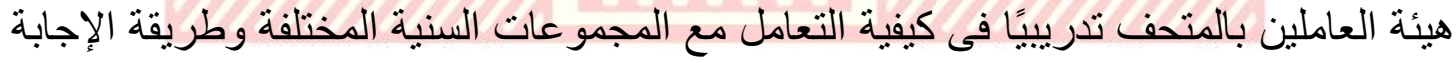
عن تساؤ لاتهم.

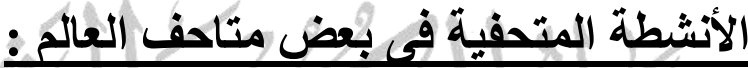 تجربة المتحف البيلئي فحى مدينة فرنسيس (فرنسا)}

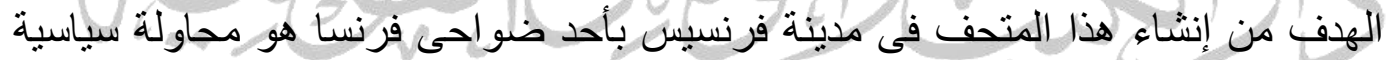

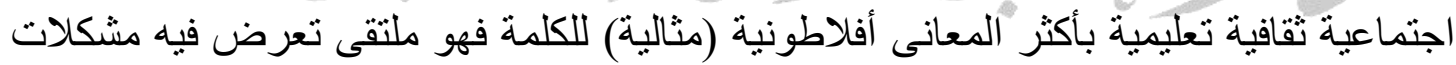

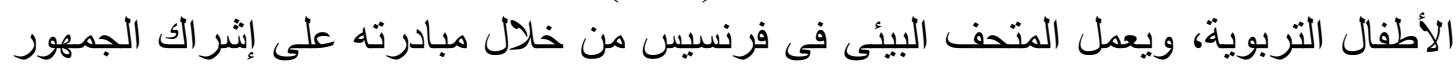

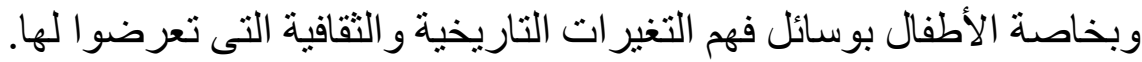

\section{الأنشطة المتحفية بمتحف بيوزنان (بولندا)}

تحتوى الأنشطة المتحفية بمتحف ببوزنان على الآتى :

ا_ـ ألعاب للأطفال تتخلص فى البحث عن ألعاب الأطفال الموجودة أو المصورة بالمتحف

$$
\text { ثم اللعب بألعاب مشابهة. }
$$


r - ــ ورشة عمل يقوم فيها الأطفال بمساعدة فنان حقيقى فى عمله وهو يكلمه عما يفعل وعن الفن عامة حصص فئ الجغر افيا و الفن.

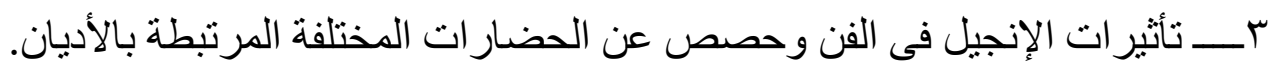
؟ـــ الرسوم السيريالية وما ترمز إليه.

$$
\text { —_ حصص أو كورسات فى فن التصوير الفوتوغر افى. }
$$

Tـــ محاضر ات يتم فيها الكلام عن لوحة دعينة مع موسيقى تعزفها أوركستر ا حية. وتقام كل شهر.

ح-ـــات رحلات ينظمها قسم التعليم المتحفى أو مدرسة المتحف للأماكن الثقافية أو المرتبطة بمجمو عات المتاحف، مثل المواقع التى جاءت منها. ^_ـ نشاطات تنظم للأطفال المكفوفين وذوى الاحتياجات الخاصة، ومنها عروض مسرحية

\section{صغيرة.}

مما سبق ينضح أن هناك أهية كبرى لدور الأنشطة الهتحفية فى بناء طفل القرن الحادى

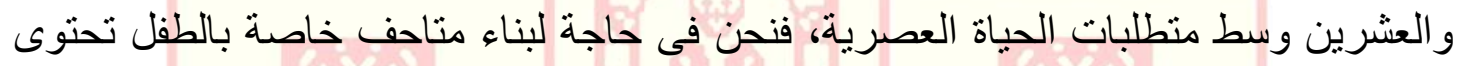

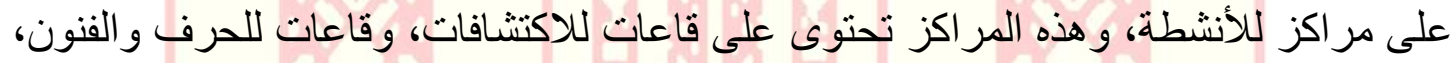
وقاعات اعرف نفسك والتى تحنوى على أجهزة لجسم الإنسان قابلة للفك و التركيب؛ فالطفل يتعلم

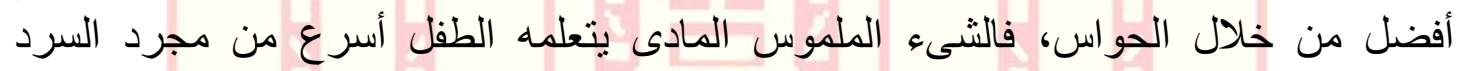

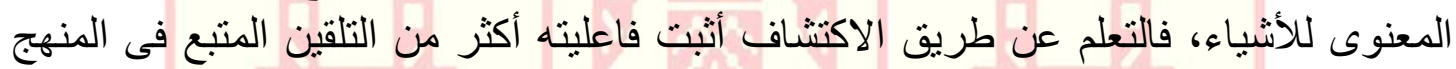

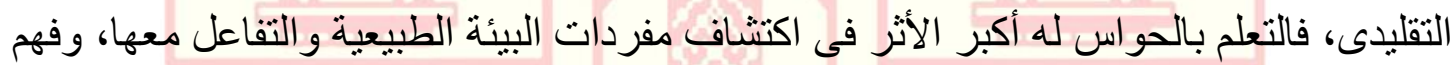

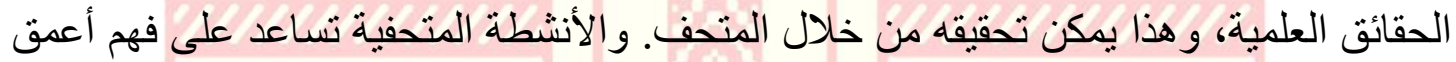

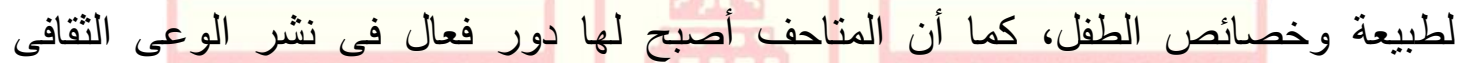

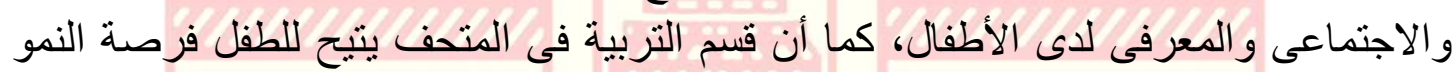

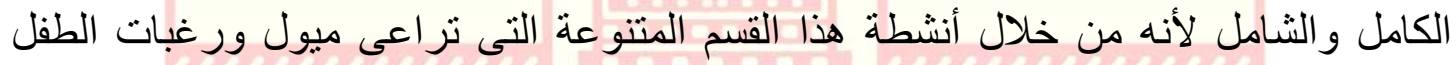

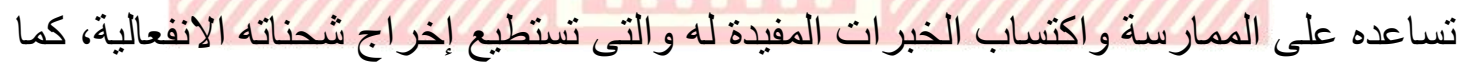

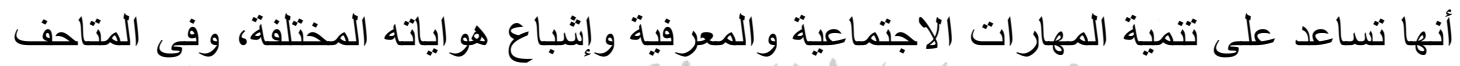

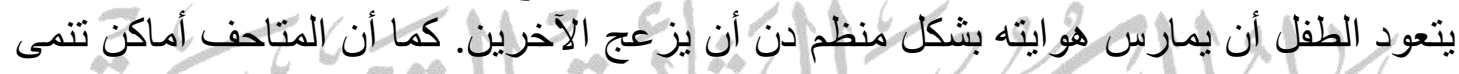

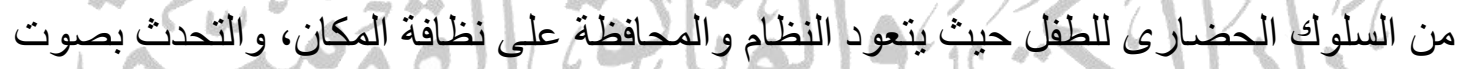

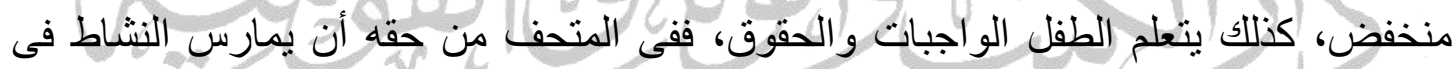

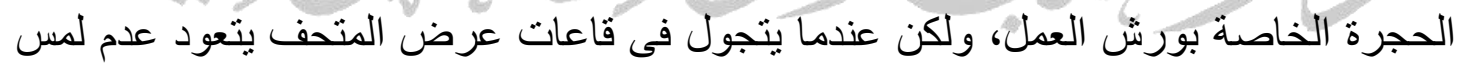
القطع الأثرية، ويلزم الهدوء بو السير في نظام.

\section{المتحف مؤسسة ثقافية}

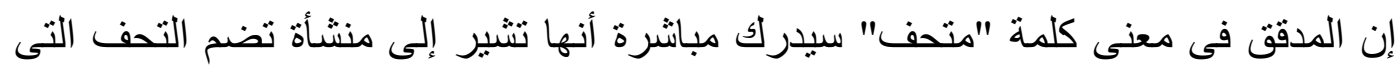

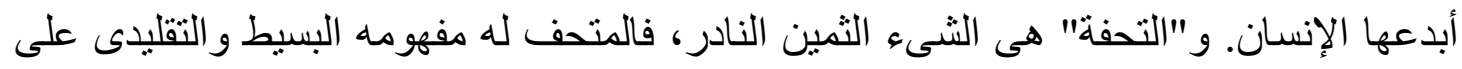

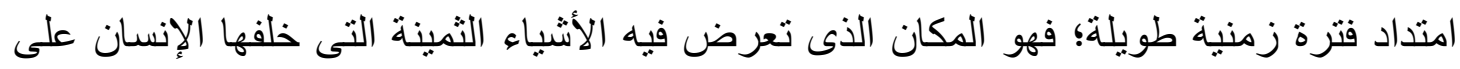

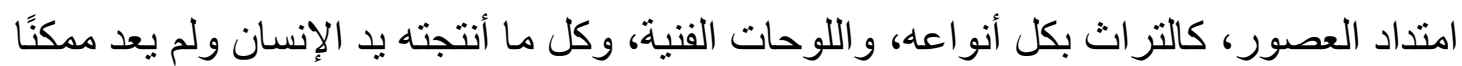


استخدامه اليوم، كقاطرات السكك الحديدية القديمة، و السيارات القديمة، و العملات، وطوابع

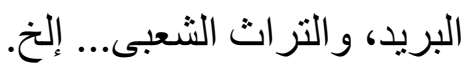

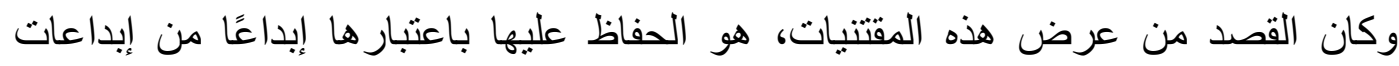

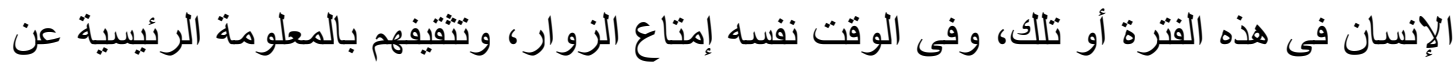

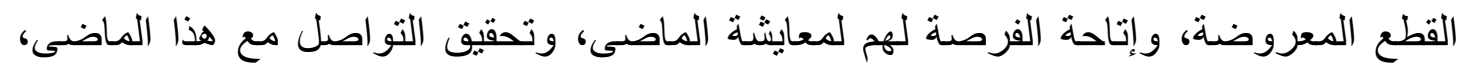

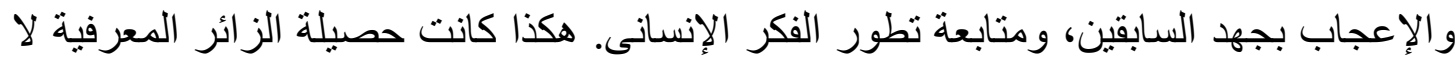

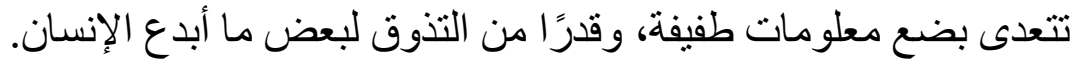

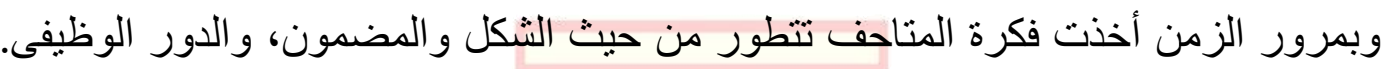

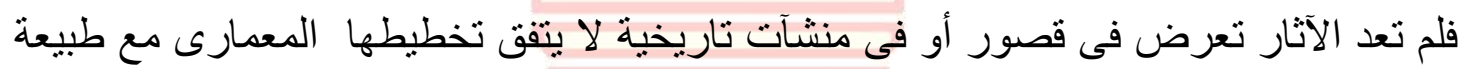

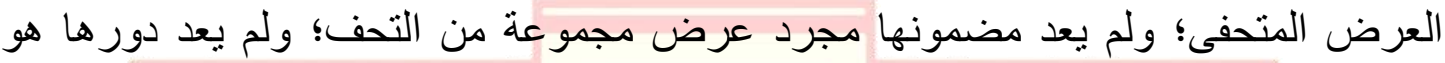
مجرد إمتاع الز ائر و إثارة الحس الفنى لديه؛ إنما تعدى دور المؤسسات المتحفية ذللك بمراحل.

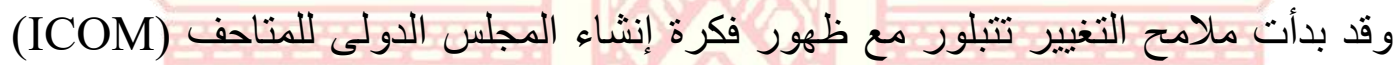

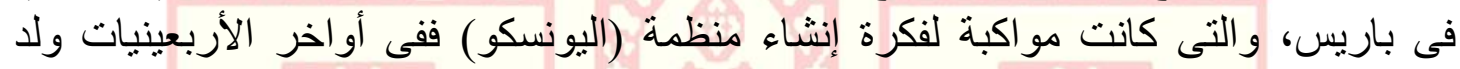

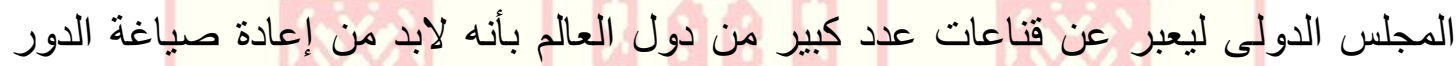

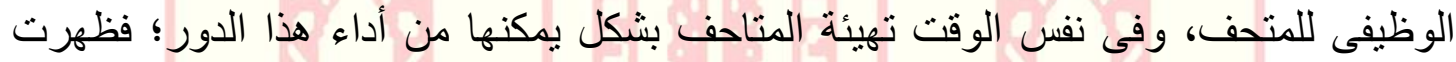

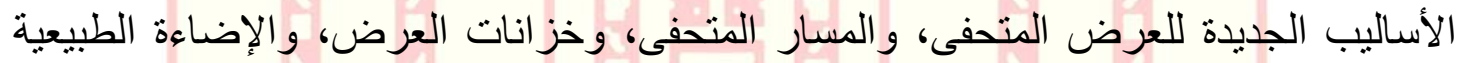

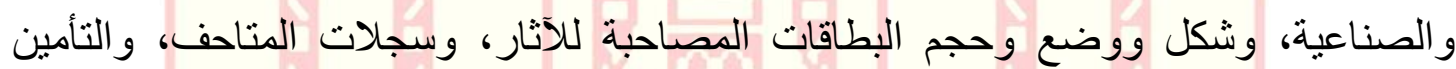

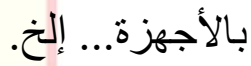

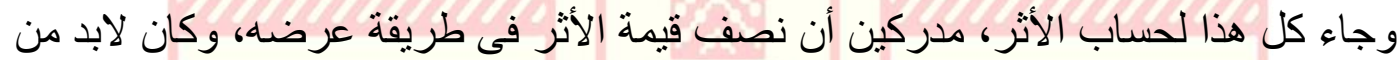

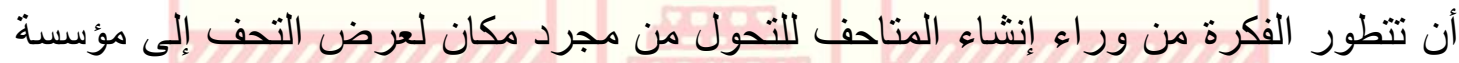
تعليمية ثقافية تكاد تكون متكاملة. ويمكنها أن تلعب دورًا مؤثرًا في مجتمعها.

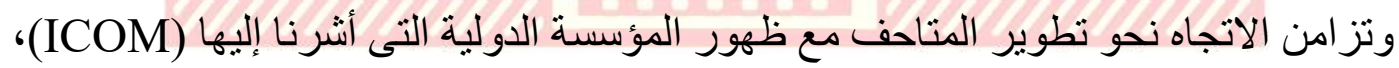

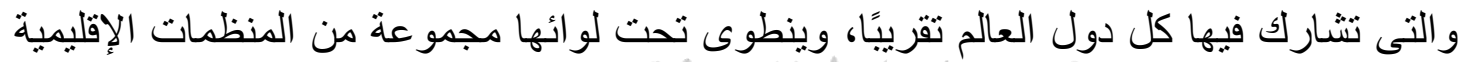

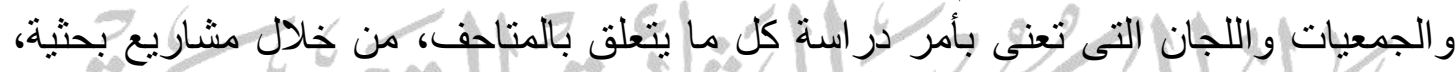

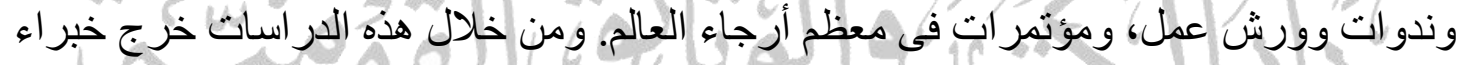

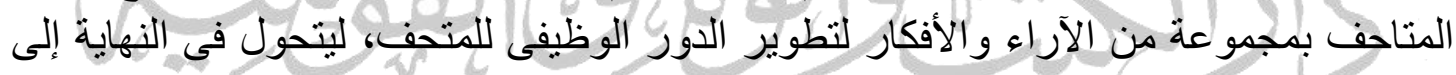
مؤسسة تقافية.

وبدأت المتاحف تتبنى قضية ربط الطفل بمقتتيات المتاحف بكل أنواعها من خلال التربية

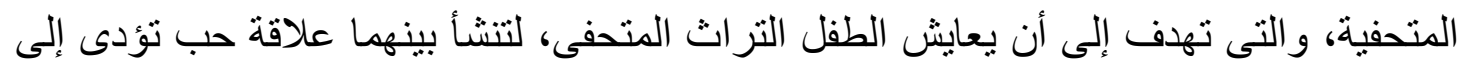

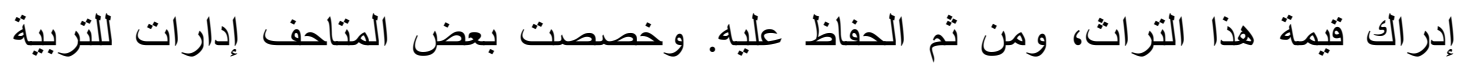

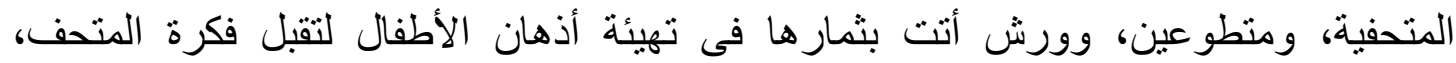

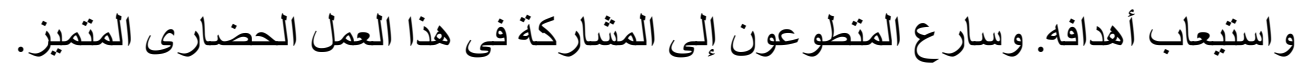
وقد جرت بعض الندوات فى هذا المجال فى مصر فى فترة التسعينات، كما جرت محاولة 
محدودة لممارسة تجربة التربية المتحفية، والأمل كبير فى أن تستمر هذه التجربة.

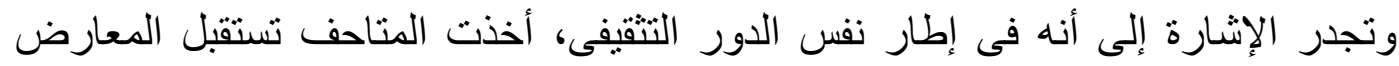

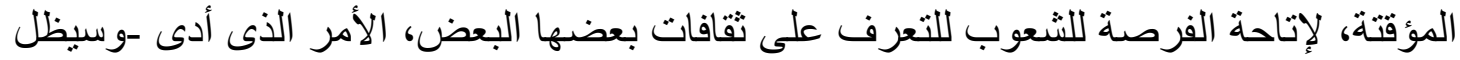

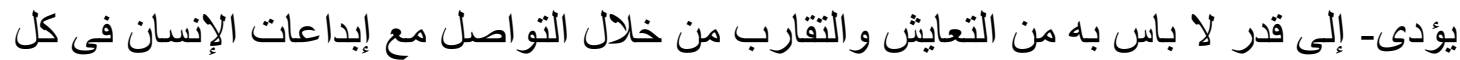

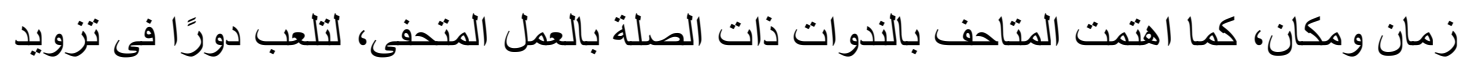

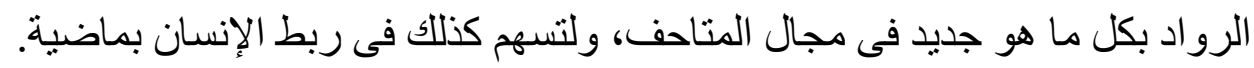

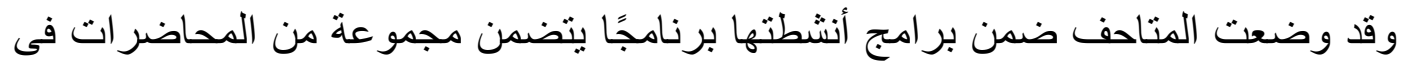

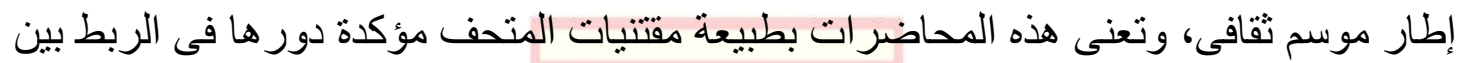

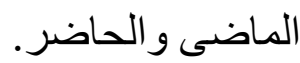

و أبدت المتاحف اهتمامًا كبيرًا بالمكتبات، حيث أصبحت مكتبات المتاحف ملاذًا أساسيًا لكثير

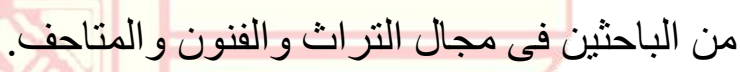

وأخذت المتاحف تلعب دورًا بارزًا في تأصيل الانتماء وإحياء الزمان، وذلك من خلال

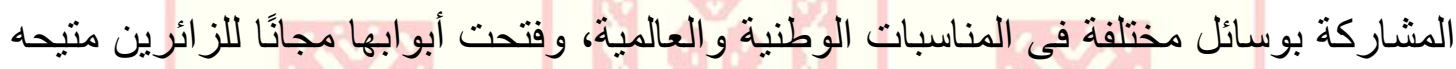

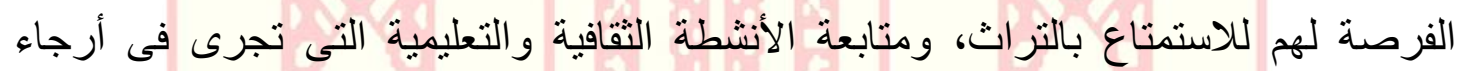

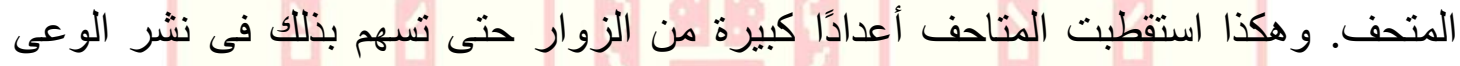

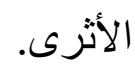
و أقدمت المتاحف على إعداد الأدلة و النشرات والأفلام و الأقراص (CD)، ولئل وغير ها من الوسائل لتقديم المعلومة فى سهولة ويسر للزائرين.

وجدير بالذكر أن بعض المتاحف قد فتحت أبوابها لأنواع مختلفة من الدورات التدريبية

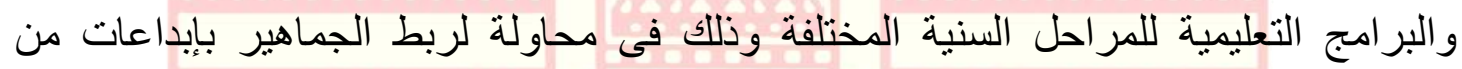

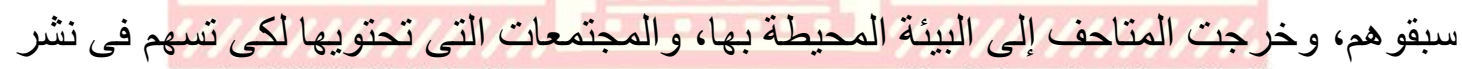
الوعى بتراث الأقدمين من خلال حملات توعية تتضمن معارض ومحاضرات وندات وندوات

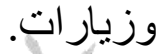

كما سعت بعض المتاحف إلى التعاون مع المؤسسات والجمعيات الحكومية و غير الحكومية

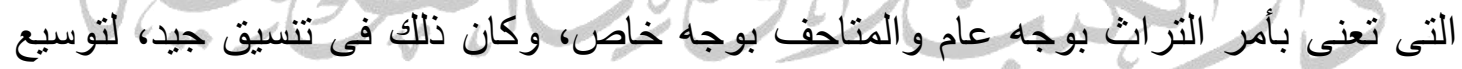
دائرة المعرفة بالمتاحف ودورها المتميز، كالمدارس والجامعات، وجمعيات أصدقاء التراث

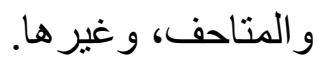

واهتمت المتاحف بإنثاء منافذ لبيع الكتب والنشرات والهدايا التذكارية المتعلقة بمقتنيات المتاحف؛ لتساعد الز ائرين على الحصول على ما يغذى اهتماماتهم فى هذا الميدان.

و هكذا يمكن القول أن المتاحف قد تخطت إلى حد كبير دورها التقليدى، وققزت قفزات

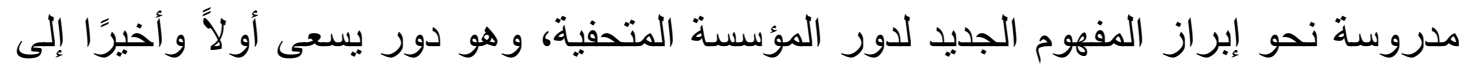

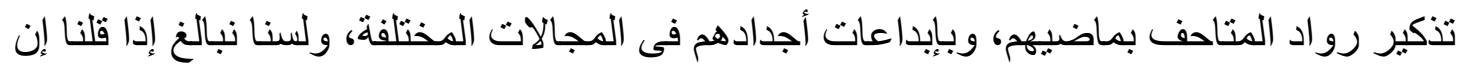


المتاحف هى أفضل الوسائل وأسر عها و أكثرها تأثيرًا فى ربط الماضى بالحاضر، ومن ثم فى

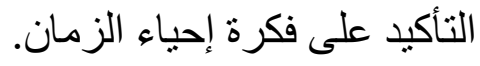

كما تجدر الإشارة إلى أن هنالك نهضة قد شهدتها متاحفنا فى السنوات العشرين الأخيرة، واتهات

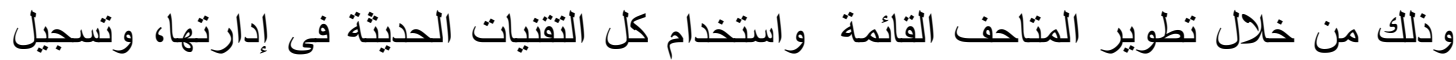

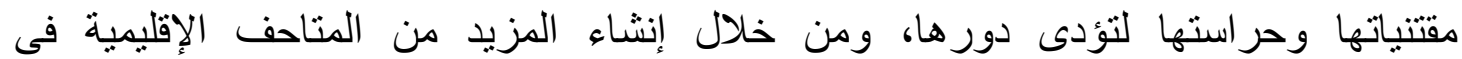

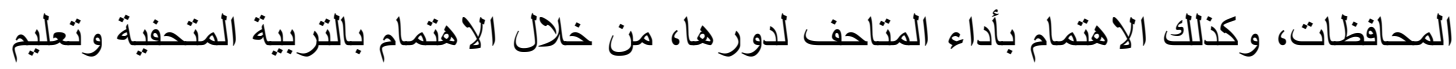

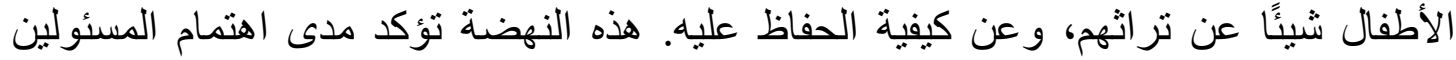
بالمتاحف وفهم العاملين بهذه المتاحف لدور المتاحف كمؤسسات تعليمية تثقيفية.
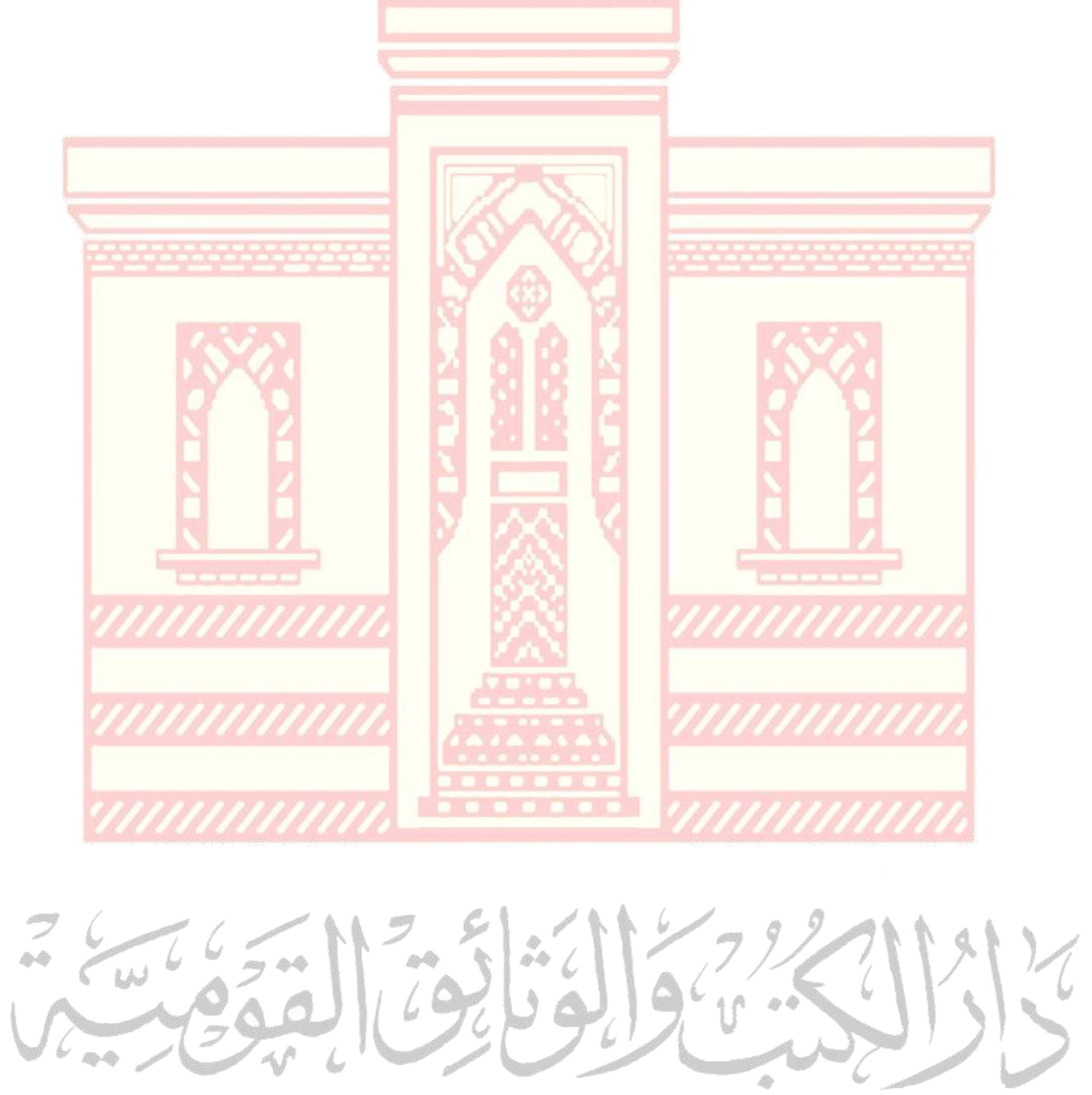